\title{
THE RESPONSE OF BURROW-NESTING PETRELS AND OTHER VULNERABLE BIRD SPECIES TO VERTEBRATE PEST MANAGEMENT AND CLIMATE CHANGE ON SUB-ANTARCTIC MACQUARIE ISLAND
}

\author{
by Nigel Brothers \& Catherine Bone \\ (with nine text-figures and 17 tables)
}

\begin{abstract}
Brothers, N. \& Bone, C. 2008 (31:x) The response of burrow-nesting petrels and other vulnerable bird species to vertebrate pest management and climate change on sub-Antarctic Macquarie Island. Papers and Proceedings of the Royal Society of Tasmania 142(1): 123-148. https://doi.org/10.26749/rstpp.142.1.123 ISSN 0080-4703. Department of Primary Industries, Water and Environment, GPO Box 44, Hobart, Tasmania 7001, Australia (NB), 178 South Arm Drive, Wonga Beach, Queensland 4873, Australia (NB*, CB) *Author and address for correspondence. Email: brothersbone@yahoo.com.au
\end{abstract}

Pest species management is causing rapid and significant changes to burrow-nesting petrel populations on sub-Antarctic Macquarie Island. The Weka, Gallirallus australis, was eliminated by 1989 and the Feral Cat, Felis catus, eradicated in 2000. The most abundant burrownesting petrel species currently, White-headed Petrels, Pterodroma lessonii, Antarctic Prions, Pachyptila desolata, and Sooty Shearwaters, Puffinus griseus, have yet to increase in numbers, but are expected to do so in the absence of cats. This study found evidence that Grey Petrels, Procellaria cinerea, began breeding again on the island in 1999, after an absence of over 100 years. Blue Petrels, Halobaena caerulea, and Fairy Prions, Pachyptila turtur, were found to be re-colonising Macquarie Island from offshore stacks after a similar absence. South Georgian Diving-Petrels, Pelecanoides georgicus, were also possibly recolonising the island. Despite the presence of Black Rats, Rattus rattus, most of the bird species discussed are considered capable of population increase. If European Rabbits, Oryctolagus cuniculus, are not eliminated or maintained in reduced numbers, some petrel populations will never fully recover. Climate change could have a negative impact on burrow-nesting petrels, and is likely to exacerbate the detrimental effects of the remaining pest species on vulnerable indigenous bird species, compounding the need for remedial action against rabbits in particular. Together with predictions that other petrel species will now return to breed, certain terrestrial bird species, alien to the region, may invade Macquarie Island as a consequence of the combination of pest eradication and changing climatic conditions.

Key Words: Burrow-nesting petrel, pest eradication, climate change, population response, Macquarie Island.

\section{INTRODUCTION}

The status of burrow-nesting petrels on Australia's subAntarctic Macquarie Island situated at $54^{\circ} 30^{\prime} \mathrm{S}, 158^{\circ} 56^{\prime} \mathrm{E}$, was reported by Brothers (1984). However, this was a period when vertebrate pest management effort directed at the European Rabbit, Oryctolagus cuniculus (Linnaeus, 1758), Feral Cat, Felis catus Linnaeus, 1758, Black Rat, Rattus rattus (Linnaeus, 1758), House Mouse, Mus musculus Linnaeus, 1758 and Weka, Gallirallus australis (Sparrman, 1786) had either made little impact, or had not yet commenced. In the following period up to 2000 , the rabbit population was dramatically reduced (Brothers et al. 1982) and maintained at a much lower level (Copson 2004), Weka were eliminated by 1989 (Copson 1995) and cats by 2000 (Copson 2002). Because these events are likely to precipitate rapid changes in the distribution, abundance and species composition of the island's avifauna, an update of the population status of monitored affected species is presented here. Further threatened species management outcomes can be assessed against this baseline information (Copson 2002, 2004, Parks and Wildlife Service 2006, Threatened Species Section 2007).

During the course of burrow-nesting petrel monitoring, the consequences of vertebrate pest management, aspects of which were the subject of earlier extensive discussion (Brothers \& Copson 1988, Scott 1988, Copson 1995, Copson \& Whinam 1998, 2001), have become complicated by the apparent impact of recent specific climatic events and trends. Tweedie \& Bergstrom (2000) discussed some of the impacts of changing climatic conditions on Macquarie Island and Chown \& Smith (1993) discussed similar impacts for the sub-Antarctic Prince Edward Islands. Already a rapid increase in temperatures over the past 50 years together with trends in other climatic features have been documented by Adamson et al. (1988) and Pendlebury \& Barnes-Keoghan (2007) for Macquarie Island. Specific observations of a climatic nature during the period of the study reported here are discussed in an attempt to ascertain the distinction between impacts of climate changes on indigenous fauna and impacts of vertebrate pest management actions alone or in combination.

The status and population trends of ten burrow-nesting seabird species from 1975-1999 are provided here. These data are examined in the context of five vertebrate pests that have invaded the island with particular emphasis on the three species (rabbits, rats and mice) remaining on the island after 2000. The effects of climate change and likely impacts on indigenous bird species and feral species are examined and discussed.

\section{MATERIALS AND METHODS}

After the initial assessment of distribution and abundance of burrow-nestingpetrels by Brothers (1984), further assessments were made in 1988 (28 October-2 December), 1993 (28 October-24 December) and in 1999 (11 November-11 February 2000). This most recent assessment was the last breeding season for the majority of seabird species during which cats were known to be present (Copson 2002). The census method followed that described in Brothers (1984), 
being tailored for the various species to suit logistics and maximise data accuracy in different habitat types, and with consideration given to the possibility that any future monitoring may be done by individuals with varying degrees of expertise. An additional factor influencing the census method design was the probability that an altered population density could change the logistics and reliability of any future census. For example, while current nesting-densities may permit efficient and accurate counting, this ability may be lost in the event of a substantial increase in nesting density and/or in the event of rabbit eradication, with the reversion of heavily rabbit-grazed habitat to ungrazed, densely vegetated habitat, which is more difficult to search. The potential of such factors to compromise the accuracy and, therefore, comparability of counts over time, determined for example, that transects were kept narrow but not necessarily short. As population monitoring was the principal objective, count areas or transect site selection was biased to localities where the different species still remained, rather than in the original main nesting areas now no longer occupied due either directly (predation) or indirectly (nesting habitat modification) to one or more of the vertebrate pest species.

For consistency, localities of transects and records of breeding colonies, followed Brothers (1984), using a $1 \mathrm{~km}^{2}$ grid system (and tenths thereof) based on the intercepts of $54^{\circ} 48^{\prime} \mathrm{S}, 158^{\circ} 45^{\prime} \mathrm{E}$ from the 1:50000 map produced by the Division of National Mapping, Canberra (fig. 1). It should be noted that this plotting method was replaced in 2000, after the island's actual geographical position was corrected (G. Copson pers. comm.).

Species population trends were measured by means of repeated counts of either established permanently marked count areas (tables 1-4) or counts of discreet colonies identified by their locality name and six-figure grid reference point (tables 5,6). This latter method was used for Sooty Shearwaters, Puffinus griseus (J.F. Gmelin, 1789), a widespread species in discreet, generally small colonies with island-wide scattered colonies that are the most accessible to all potential predators. Thus, Sooty Shearwaters were considered to be the best potential overall indicator of pest and pest-management impacts on petrels during this period. A sub-sample only of all Sooty Shearwater colonies was used to indicate population trends, because of uncertainty as to whether some newly-discovered colonies were new or overlooked previously in terrain and habitat that readily conceals burrows. Population trends were calculated from the difference between each separate year when counts were done. Consistent with the methods described by Brothers (1984), a burrow that showed signs of recent occupation was considered indicative of one potential breeding pair.

The first permanently-marked population monitoring sites were established in 1988 and were primarily for Antarctic Prions, Pachytila desolata (J.F. Gmelin, 1789), and White-headed Petrels, Pterodroma lessonii (Garnot, 1826). For prions, two $100 \mathrm{~m} \times 200 \mathrm{~m}$ (fig.1) rabbit population monitoring count areas (Copson et al. 1981) were initially selected because not only were prions known to breed within them, but because any relationship between prion and rabbit abundance was likely to become apparent, as rabbit counts have been maintained at these sites for over 25 years (Copson 2004). These count areas, one at Prion Lake, the other at South Square Lake, had their boundaries marked with plastic pipe. Burrows were counted $5 \mathrm{~m}$ each side of a line between all corner markers as well as dissecting across from the centre of each side of the count

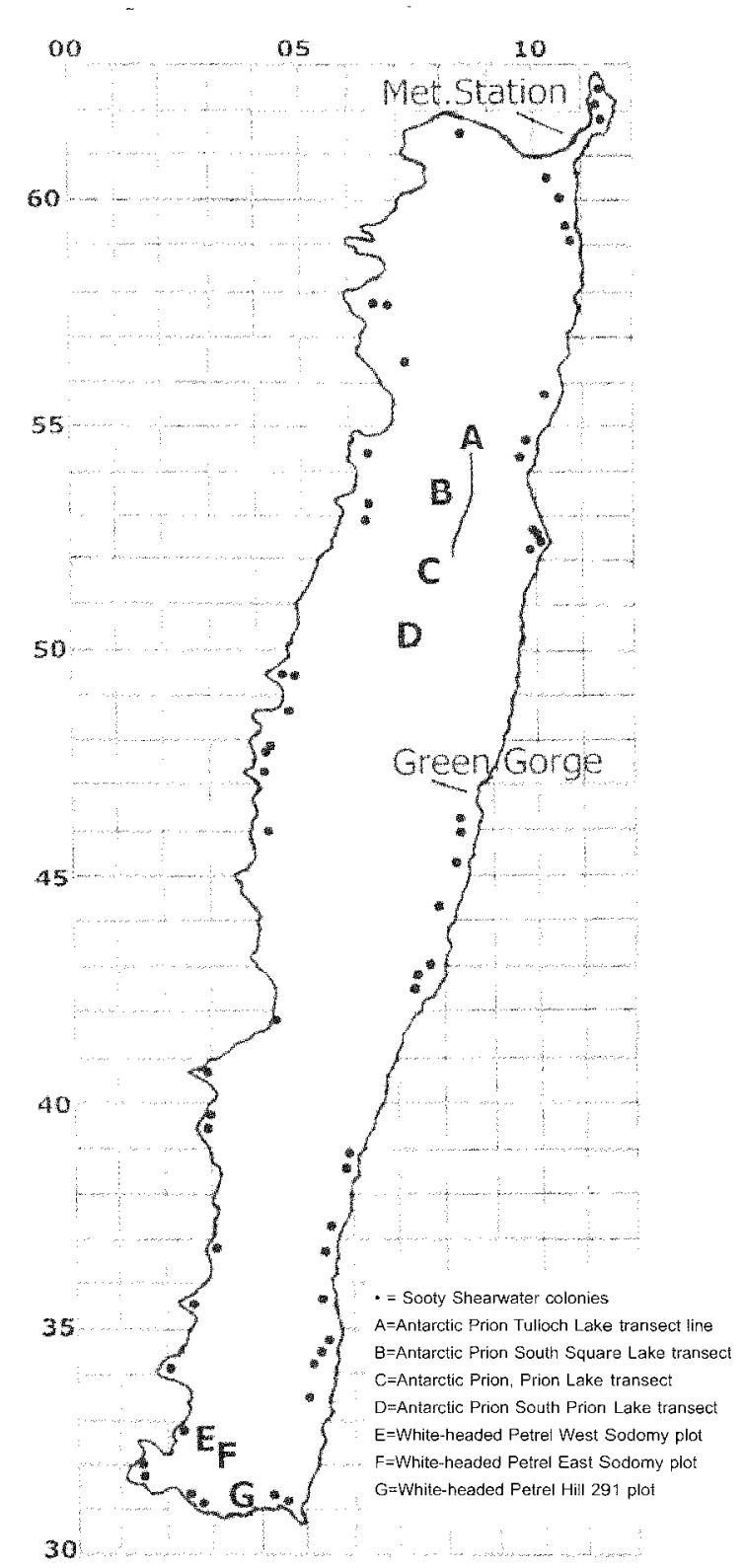

FIG. 1 - Macquarie Island with the $1 \mathrm{~km}^{2}$ numbered grid system for colony site identification, the location of petrel monitoring sites, Sooty Shearwater colonies, and the Green Gorge and Meteorological Station rainfall observation sites.

area. South Prion Lake monitoring site (fig. 1, table 1), a straight $250 \mathrm{~m} \times 10 \mathrm{~m}$ transect with a mid-line that had a plastic pipe marker at 50 -m intervals, was not established until 1999. The track section between the outflow of Tulloch Lake and the Bauer Bay to Sandy Bay track intersection ("Fourways"), a distance of approximately $2 \mathrm{~km}$, was chosen in 1988 to monitor changing prion abundance. This area was considered to have abundant suitable but as yet little occupied habitat. Transect width was $2.5 \mathrm{~m}$ and situated on each side of the track.

Counts at prion monitoring sites were undertaken between late November and early December in each year, the period of greatest burrowing activity. For the count years of 1993 and 1999, prion call playback tapes were used in an attempt to improve burrow occupancy counts, ascertain the extent of multiple pairs using one burrow entrance and determine the 
extent to which rabbit burrows on transects were occupied by prions. Although prions are known to frequently exploit rabbit burrows for nesting (Brothers 1984) the extent of this is not easily ascertained. Therefore, counts were maintained of various burrow types from which a response was generated by call playback (table 1). Each burrow entrance was subjected to call playback for 5 seconds with negative and positive responses noted (table 1 ).

The first permanently-marked White-headed Petrel monitoring plots were established in 1993. One at 031312, in herbfield habitat, extending $50 \mathrm{~m}$ downhill to the east of Hill 291 summit (fig. 1), $50 \mathrm{~m}$ across the slope northwards with the third boundary then running back to Hill 291 summit, forming a triangle. This area for many years (at least since 1975) has been denuded of Poa foliosa (Hook. f.) tussock by rabbit grazing. The other, a rectangular plot in un-grazed tussock at the western end of Sodomy Ridge (023326) marked with plastic pipes, extends east-west for 60 $\mathrm{m}$ and is $5 \mathrm{~m}$ in width. An additional White-headed Petrel monitoring plot (approximately $20 \mathrm{~m}^{2}$ ) was established in 1999 further east on Sodomy Ridge (025326) and marked with plastic pipes. At this time dense tussock covered the northern half of the plot, but the southern half had been partially destroyed by rabbit grazing, with adjacent vegetation being heavily impacted. Counts of White-headed Petrels were made through the last half of November into December with active burrows remaining obvious into January.

For other species populations, only estimates are available. These were based on the extent and abundance of nesting sites. More accurate counts were not possible due to the duration and timing of visits, the nature of nesting habitat, or due to the extent of interconnected burrows characteristic of the colonies on offshore stacks. Numbered metal leg bands were used to help ascertain Fairy Prion, Pachyptila turtur (Kuhl, 1820), numbers where several birds used the same rock crevice entrance access, concealing nest sites within. The implications of the 1999 population monitoring results were assessed in relation to total island population estimates for each species resulting from work between 1975 and 1982 (Brothers 1984). Some data of single year counts have been included for comparison with potential future counts.

Searches of all potential petrel-nesting areas were undertaken in each survey period to reveal newly established nesting sites for different species. Extensive spotlight searches together with systematic examination of petrel carcasses were used to further indicate the presence of particular species.

Throughout the seabird monitoring study, that commenced in November 1975, there has been visual evidence of ecological responses to changing climatic conditions. In an attempt to substantiate these observations and identify potential causes of the changes observed, records maintained by the Australian Bureau of Meteorology were examined for trends in climatic conditions around Macquarie Island. Records between 1948 and 2006 were used, but for some weather components, due to problems with data accuracy or missing data in earlier years, records between 1968 and 2006 were examined.

Of particular relevance to the study were changes in the amount and pattern of precipitation at Macquarie Island, specifically in relation to petrel burrow flooding events, and the frequency of events such as sustained lower temperatures, that impact on pest species survival. Weather data were used to ascertain whether the documented trend prior to 1986 of more northerly prevailing wind direction (Adamson $e t$ al. 1988) has continued, intensified or ceased.
The relationship between rainfall and petrel burrow flooding events is a very important factor in the abundance of petrel species and their relationship to rabbits. Observed flooding events were correlated with rainfall amounts over the previous 24 hours. In addition, eight sets of $3 \times 50$-cm-deep water table level monitoring holes were dug across representative habitat of varying topography containing burrows. Water levels and associated rainfall amounts could only be obtained intermittently at the Green Gorge study site. To avoid complicating the results, only an equal number of water table readings obtained in each rainfall category have been used. More extensive and complex investigations would be necessary to fully ascertain variability and relationships between water table levels and rainfall. However, where additional duplicate water table readings were included, the pattern of water table response was consistent. This indicates that the small data set available is adequate to demonstrate, at least in a limited way, the relationship between rainfall amounts and burrow flooding events. All water table levels decreased below $50 \mathrm{~cm}$ (the depth of each measurement site) were not included for analysis except when determining water table levels relative to a nominal burrow depth of $25 \mathrm{~cm}$. Surface water table levels $(0 \mathrm{~cm})$ were included when calculating the average rate of rise or decline in water level.

The limited rainfall observations made at Green Gorge were compared with data from the meteorological station $15 \mathrm{~km}$ to the north to ascertain whether water table level fluctuations or observations of burrow flooding events anywhere on the island correlated with rainfall. More precise comparisons between rainfall recorded at the Bureau of Meteorology weather station and Green Gorge were constrained as rainfall records for Green Gorge were taken at slightly different time intervals to those at the station. In addition, rainfall records at Green Gorge were taken to the nearest $1.0 \mathrm{~mm}$ with any amount less than $1.0 \mathrm{~mm}$ being recorded as trace only, whereas station records were taken to the nearest $0.2 \mathrm{~mm}$. However, this would have created only a minor discrepancy between rainfall observations at the two sites. The Bureau of Meteorology weather station observations are taken near sea level at the island's northern end, and therefore could be atypical of the rest of the island and may not provide data that reflect weather impacts on the island as a whole.

\section{RESULTS}

\section{White-headed Petrel, Pterodroma lessonii (Garnot, 1826)}

From 1993-1999, there was an apparent decline in Whiteheaded Petrel burrow occupancy of 20-30\% (table 4). Brothers (1984) showed that White-headed Petrels were highly susceptible to disturbance by rabbits, and these figures assume that the seven burrows at Hill 291 in 1999, occupied by both rabbits and petrels, were not retained by the petrel. Rabbit numbers and associated vegetation damage in the vicinity of these monitoring plots remained high relative to other White-headed Petrel nesting areas. Therefore the decline in the number of active burrows in other areas since the 1970s surveys (Brothers 1984) is likely to be due to cat predation, rather than the impact of rabbits. Cat predation of petrels intensified during the period when myxomatosis was introduced to kill rabbits, which resulted in lower food availability for cats in these areas. 
TABLE 1

Antarctic Prion monitoring burrow counts on 18 transects at four localities, between 1988 and 1999 on Macquarie Island

\begin{tabular}{|c|c|c|c|c|c|c|c|c|c|c|c|c|c|c|c|c|c|c|c|c|c|}
\hline \multirow[b]{3}{*}{ Year } & \multicolumn{3}{|c|}{$\begin{array}{l}\text { Occupied prion } \\
\text { burrows }\end{array}$} & \multicolumn{3}{|c|}{$\begin{array}{c}\text { Unoccupied } \\
\text { prion } \\
\text { burrows }\end{array}$} & \multicolumn{3}{|c|}{$\begin{array}{l}\text { Prion in } \\
\text { rabbit } \\
\text { burrows }\end{array}$} & \multicolumn{3}{|c|}{$\begin{array}{l}\text { Rabbit only } \\
\text { burrows }\end{array}$} & \multicolumn{3}{|c|}{$\begin{array}{c}\text { White- } \\
\text { headed petrel } \\
\text { burrows }\end{array}$} & \multicolumn{6}{|c|}{$\begin{array}{l}\text { Burrow occupancy indicated by prion } \\
\text { call response }\end{array}$} \\
\hline & \multirow[b]{2}{*}{88} & \multirow[b]{2}{*}{93} & \multirow[b]{2}{*}{99} & \multirow[b]{2}{*}{88} & \multirow[b]{2}{*}{93} & \multirow[b]{2}{*}{99} & \multirow[b]{2}{*}{88} & \multirow[b]{2}{*}{93} & \multirow[b]{2}{*}{99} & \multirow[b]{2}{*}{88} & \multirow[b]{2}{*}{93} & \multirow[b]{2}{*}{99} & \multirow[b]{2}{*}{88} & \multirow[b]{2}{*}{93} & \multirow[b]{2}{*}{99} & \multicolumn{3}{|c|}{ Prion burrow } & \multicolumn{3}{|c|}{ Rabbit burrow } \\
\hline & & & & & & & & & & & & & & & & 88 & 93 & 99 & 88 & 93 & 99 \\
\hline \multicolumn{22}{|l|}{ Prion Lake } \\
\hline North side & 29 & 51 & 32 & 0 & 0 & 1 & 1 & 0 & 7 & 2 & 2 & 5 & 0 & 0 & 0 & - & $15(1)^{1}$ & $15(3)$ & - & 0 & $7(3)$ \\
\hline South side & 27 & 26 & 12 & 0 & 0 & 5 & 1 & 2 & 4 & 0 & 3 & 3 & 0 & 1 & 0 & - & 13 & 3 & - & 2 & 4 \\
\hline East side & 8 & 23 & 6 & 0 & 0 & 0 & 1 & 0 & 1 & 0 & 0 & 2 & 0 & 0 & 0 & - & 9 & 2 & - & 0 & 1 \\
\hline West side & 22 & 25 & 10 & 0 & 0 & 1 & 0 & 1 & 2 & 0 & 1 & 4 & 0 & 0 & 0 & - & 9 & $8(3)$ & - & 1 & $2(2)$ \\
\hline $\begin{array}{l}\text { Centre north/ } \\
\text { south }\end{array}$ & 12 & 16 & 10 & 0 & 0 & 0 & 0 & 0 & 2 & 2 & 1 & 5 & 0 & 1 & 0 & - & 3 & 4 & - & 0 & $2(2)$ \\
\hline $\begin{array}{l}\text { Centre east/ } \\
\text { west }\end{array}$ & 13 & 13 & 14 & 0 & 0 & 1 & 1 & 0 & 1 & 0 & 1 & 1 & 0 & 0 & 0 & - & 3 & $8(3)$ & - & 0 & 1 \\
\hline Total & 111 & 154 & 84 & 0 & 0 & 8 & 4 & 3 & 17 & 4 & 5 & 20 & 0 & 2 & 0 & & 53 & 49 & & 3 & 24 \\
\hline \multicolumn{22}{|l|}{ Square Lake } \\
\hline North side & 0 & 0 & 0 & 0 & 0 & 0 & 0 & 0 & 0 & 0 & 0 & 0 & 0 & 0 & 0 & - & 0 & & - & 0 & 0 \\
\hline South side & 15 & 9 & 16 & 0 & 0 & 1 & 0 & 4 & 0 & 0 & 5 & 3 & 0 & 0 & 0 & - & $7(2)$ & 7 & - & 4 & 0 \\
\hline East side & 20 & 8 & 25 & 0 & 0 & 0 & 0 & 3 & 1 & 1 & 12 & 3 & 1 & 0 & 1 & - & $5(2)$ & 11 & - & 3 & 1 \\
\hline West side & 19 & 14 & 21 & 0 & 0 & 7 & 5 & 4 & 0 & 3 & 21 & 6 & 0 & 1 & 1 & - & $8(1)$ & $13(2)$ & - & 4 & 0 \\
\hline $\begin{array}{l}\text { Centre north/ } \\
\text { south }\end{array}$ & 16 & 13 & 21 & 0 & 0 & 1 & 0 & 0 & 0 & 0 & 11 & 4 & 0 & 2 & 0 & - & 3 & $8(1)$ & - & 0 & 0 \\
\hline $\begin{array}{l}\text { Centre east/ } \\
\text { west }\end{array}$ & 7 & 4 & 9 & 0 & 0 & 0 & 0 & 3 & 1 & 1 & 4 & 1 & 0 & 0 & 0 & - & 5 & $6(2)$ & - & 3 & 1 \\
\hline Total & 77 & 48 & 92 & 0 & 0 & 9 & 5 & 14 & 2 & 6 & 53 & 17 & 1 & 3 & 2 & & 33 & 50 & & 14 & 2 \\
\hline Tulloch Lake & 30 & 38 & 56 & 0 & 0 & 13 & 0 & 1 & 12 & 0 & 11 & 29 & 0 & 2 & 2 & - & - & $15(3)$ & - & 1 & $12(2)$ \\
\hline Overall Totals & 218 & 240 & 232 & 0 & 0 & 26 & 9 & 18 & 31 & 10 & 69 & 66 & 1 & 7 & 4 & & 86 & 117 & & 18 & 40 \\
\hline Prion Soutb & - & - & 31 & - & - & 1 & - & - & 6 & - & - & 5 & - & - & 0 & - & - & $21(1)$ & - & - & $6(2)$ \\
\hline
\end{tabular}

1 Parentheses indicate additional pairs within same burrow detected by call playback response.

TABLE 2

Comparative rate of Antarctic Prion population change

\begin{tabular}{|c|c|c|c|c|c|c|}
\hline \multirow[t]{2}{*}{ Basis of count } & \multicolumn{3}{|c|}{ Total counts } & \multicolumn{3}{|c|}{$\%$ change 1} \\
\hline & 1988 & 1993 & 1999 & $1988-93$ & $1993-99$ & $1988-99$ \\
\hline Occupied prion burrows & 218 & 240 & 232 & $>10.0$ & $<3.0$ & $>6.4$ \\
\hline $\begin{array}{l}\text { Occupied prion plus prion in } \\
\text { rabbit burrows }\end{array}$ & 227 & 258 & 263 & $>13.7$ & $>1.9$ & $>15.9$ \\
\hline $\begin{array}{l}\text { Call playback response from } \\
\text { prion burrows }\end{array}$ & - & 86 & 117 & - & $>36.0$ & - \\
\hline $\begin{array}{l}\text { Call playback response from } \\
\text { prion burrows plus rabbit } \\
\text { burrows }\end{array}$ & - & 104 & 157 & - & $>51.0$ & - \\
\hline
\end{tabular}

${ }^{1}$ Calculated using combinations of the burrow count and call playback response data, all sites combined from which data were collected (from table 1). 
TABLE 3

Antarctic Prion occupancy rate ${ }^{1}$ of rabbit burrows with and without the use of call playback

\begin{tabular}{lcccc}
\hline & $\begin{array}{c}\text { Occupied prion } \\
\text { burrows }\end{array}$ & $\begin{array}{c}\text { Rabbit burrow } \\
\text { without prion }\end{array}$ & $\begin{array}{c}\text { Prion occupied rabbit } \\
\text { burrows from call } \\
\text { playback response }\end{array}$ & $\begin{array}{c}\text { Prion occupied rabbit } \\
\text { burrows without call } \\
\text { playback response }\end{array}$ \\
\hline $\begin{array}{l}\text { 1988 Prion, Square, } \\
\text { Tulloch - transect dara } \\
\text { combined }\end{array}$ & 218 & 10 & - & 9 \\
1993 and 1999 Prion, & 503 & 140 & 66 \\
$\begin{array}{l}\text { Square, Tulloch and } \\
\text { Prion South transect } \\
\text { data combined }\end{array}$ & & & \\
\hline
\end{tabular}

${ }^{1}$ Based on selected data from 18 transects at four sites on Macquarie Island between 1988 and 1999 (from table 1).

TABLE 4

Burrow counts at monitoring plots for White-headed Petrels on Macquarie Island in 1993 and 1999

\begin{tabular}{|c|c|c|c|c|c|c|}
\hline \multirow[t]{2}{*}{ Site } & \multirow[t]{2}{*}{ Year } & \multicolumn{4}{|c|}{ Burrow Counts } & \multirow{2}{*}{$\begin{array}{l}\text { Total } \\
\text { Petrel }\end{array}$} \\
\hline & & Occupied & Unoccupied & $\begin{array}{l}\text { Petrel and } \\
\text { rabbit }\end{array}$ & Rabbit & \\
\hline \multirow[t]{2}{*}{ Hill 291} & 1993 & 27 & 3 & 0 & 3 & 27 \\
\hline & 1999 & 18 & 0 & 7 & 15 & 25 \\
\hline Sodomy West & 1993 & 22 & 0 & 0 & 0 & 22 \\
\hline 023326 & 1999 & 17 & 0 & 0 & 8 & 17 \\
\hline Sodomy East & 1993 & - & - & - & - & - \\
\hline 025326 & 1999 & 42 & 0 & 0 & 0 & 42 \\
\hline
\end{tabular}

Three White-headed Petrel population sites were monitored. Vegetation cover differed between sites over time because of rabbit grazing in two of the three sites. This had a variable influence on petrel abundance. Hill 291 site changed little, if at all, since 1975, as it was almost entirely denuded of tussock. West Sodomy was ungrazed by rabbits from before 1975 until 1993. However, by 1999 the vegetation became thinner and more stunted, possibly due to climatic conditions. Similarly, East Sodomy was dense tussock until at least 1993. However, by 1999 the southern half (with few burrows) had sparse tussock remaining, whereas the northern half was still relatively healthy. If a combination of results from Hill 291 and Sodomy West is indicative of an overall population trend, then from 1993-1999 a decline from 7890 breeding pairs to around 6800 has occurred on the island, assuming the original population estimate (Brothers 1984) remained stable up to 1993 . However, the sample size of these two sites is small relative to the total island population.

\section{Antarctic Prion, Pachytila desolata (J.F. Gmelin, 1789)}

There appears to have been a $6 \%$ increase in the number of occupied burrows between 1988 and 1999. This figure is based on comparison between years, by combining count data of occupied prion burrows from Prion Lake, Square Lake and Tulloch Lake (table 1). Whilst the increase from 1988 to 1993 was $10 \%$ and numbers declined by $3 \%$ from 1993 to 1999 , inter-year comparisons between sites or between individual transects within a site, showed numbers could fluctuate considerably. Much of this fluctuation appeared to be related to rabbit activity, with a decrease in occupied prion burrows occurring when more rabbit burrows were present (table 1). It is not known how many prions utilise rabbit burrows for breeding and given that the rabbit population does fluctuate, prion numbers based on "occupied burrows" may only appear to be fluctuating. If call playback response is indicative of occupancy rate then this can only account for between $7 \%$ and $15 \%$ being present yet occupying rabbit burrows. This is the proportion of all prion-occupied burrows where prion call response in both 1993 and 1999 was from a rabbit burrow (derived from the counts of occupied prion burrows plus prion in rabbit burrows) (table 1).

If call playback response only is used as the measure of occupancy irrespective of burrow type, then the number of burrows occupied by Antarctic Prions increased by 30\% at Prion Lake, 11\% at Square Lake or by $18 \%$ overall between 1993 and 1999. However, over the same period, based on the sum of "occupied prion burrows" and "prions in rabbit burrows" at Prion Lake, the population decreased by 36\%, and increased by $52 \%$ at Square Lake (table 1). By using combined area counts the estimate was of an overall $16 \%$ increase, 14\% occurring between 1988 and 1993 and 2\% 
between 1993 and 1999 (table 2). This is not evident from an estimate based solely on the call response rate (table 2) Given that the pattern of daily burrow occupancy by individuals that are not actually breeding (deferred or failed breeders, immature or unpaired birds) has been observed to vary greatly in response to daily wind strength and direction as well as moon phase, this is to be expected.

In 1988, the only year when call playback response was not used to differentiate prion-occupied and prion-unoccupied rabbit burrows, the proportion of rabbit burrows assessed as occupied by prions was $47 \%$ but this accounted for only $4 \%$ of the total count of occupied prion burrows in that year (table 3). Call playback response revealed 32\% of rabbit burrows to contain prions, which if added to the total of occupied prion burrows represented $11.6 \%$ of the total number of prions counted. The correlation between rabbit burrows assessed as occupied by a prion using manual methods and the voice callback generated from these burrows, was not assessed. Call playback response revealed two or more pairs in occupied prion burrows on 23 out of 180 occasions (15\%) but more frequently, 9 in 49 occasions, $(22 \%)$ in prion-occupied rabbit burrows (table 1 ). Out of 23 occasions when more than one pair was in the prion burrow, there were two breeding pairs, except for two occasions when three pairs responded. More than one pair was defined by call response from individuals at discernibly different positions within a burrow system.

By the time prion transects were established, rabbits had become very scarce in these areas (Copson 2004). Therefore prion burrow entrances were already becoming increasingly inconspicuous due to vegetation (particularly Acaena sp.) becoming taller, denser and more widespread without rabbit grazing, and with increased growth of lichens and mosses at burrow entrances further disguising evidence of occupancy. It is important to note that further habitat changes impacting on monitoring accuracy are likely in the future, especially if rabbits are eradicated.

The absence of burrows on sections of transects or whole transects (e.g., on the north side of Square Lake) was due to unsuitable habitat, usually water-saturated vegetated ground (mires). Few burrows occur in feldmark but this was sparse and only encountered on the Tulloch Lake transect, with the majority of all sites being dominated by a mix of short grassland and herbfields. Some minor effect on future monitoring is likely to result from a recovery of Pleurophyllum hookeri Buchanan and, in particular, Acaena megellanica (Lam.) Vahl. at these sites. Copson \& Whinam (1998) found that, without rabbits, existing species of plants became more luxuriant in the first three years, after which relative species abundance also changed.

Assuming that the $16 \%$ average increase in abundance at monitored sites is indicative of overall trends and that the earlier population estimate of 48900 pairs (Brothers 1984) remained stable up to 1993 , the 1999 estimate would be around 56700 breeding pairs of Antarctic Prions on Macquarie Island.

\section{Sooty Shearwater, Puffinus griseus (J.F. Gmelin, 1789)}

A total of 66 colonies of this species were located, with ten of these containing no active burrows in 1999 and one colony with no active burrows on previous counts, again containing occupied burrows (table 5). At 19 sites (identified in table 5 by the number in parentheses following the colony name), burrows occurred in disconnected patches too close to identify separately by grid reference. A total of 40 such patches (discounting the locality identifier patch itself) were identified, many having been created by overall colony deterioration through rabbit activity and vegetation destruction (e.g., at South Coast West)

The incidence of severe rabbit damage was greatest at the time of the 1999 census when 35\% (23 of 66 colonies) were affected with a further $18.2 \%$ (i.e., 12) being either moderately or lightly damaged. In addition, a further 12 colonies had been subjected to severe rabbit damage at some stage in the past (table 5). Of 18 severely rabbit-damaged colonies, for which comparable counts were made, a $61 \%$ decline occurred by 1993, whereas ten severely damaged since 1993 (most of these probably not until 1998 or 1999) had not yet declined. An increase of $13 \%$ occurred at the 11 colonies moderately or lightly damaged by rabbits between 1993 and 1999 but a decline of 7\% occurred at the five colonies that had not been rabbit-damaged during this period.

Based on total burrow counts the shearwater population has declined by 36\% from a pre-1979 estimate of 1806 pairs to a 1999 estimate of 1147 pairs (table 5). However, since 1979 an additional 27 colonies containing 361 pairs have been located, which, if subtracted from the 1999 total suggests that the decline, could be as high as $56.5 \%$. However, at least nine (indicated in table 5) and possibly more of the 27 "new" colonies may contain birds from existing colonies that declined in numbers over this period. There was an $89 \%$ decline at one colony alone (South Coast West) that originally contained around one-third of the total island population.

Using only counts taken both prior to 1979 and in 1999 (table 6) at colonies considered most representative and reliable (smaller colony size and lower burrow density enabling better count accuracy), a decline of $20 \%$ occurred overall. In this sample, at seven colonies, numbers increased overall by $54 \%$ whereas in 22 others an increase of $38 \%$ occurred overall. A further sub-sample (indicated in table 6) of only those colonies for which a count was made in each census year indicates a decline in nine of the ten colonies, of $45.8 \%$ overall. The same data in table 1 also suggest the majority of the decline occurred in the period between 1979 and 1988, that of 53\% over nine of the ten colonies. Subsequently, numbers increased, in seven of the ten colonies from 1988 to 1993 by $33 \%$ and by a further $12 \%$ in seven colonies from $1993-1999$.

\section{Grey Petrel, Procellaria cinerea J.F.Gmelin, 1789}

There was no evidence of Grey Petrels attempting to resume breeding on the island until 1993 despite periods of intensive searching since 1976. In November 1993 a total of 11 burrows at four sites (table 7) revealed evidence of having been occupied, feathers of this species being found at each burrow as well as four dead adults that had at least been chewed on, if not killed, by cats. Between 1993 and 1999 the species resumed breeding for the first time and did so successfully in 1999 with signs that four chicks may have fledged from a total of 12 burrows (at seven sites) that revealed signs of occupation (table 7). Based on data in Schulz et al. (2005), the chicks could have fledged within several weeks of 23 November 1999 when the first sign of their presence was found. 
At two of the three sites occupied in 1993, there was no evidence of the species' presence in 1999. The typical cavernous Grey Petrel burrow at the second colony in table 7 was, in 1999, occupied by a Pacific Black Duck, Anas superciliosa J.F. Gmelin, 1789, incubating seven eggs.

All burrows considered to have fledged chicks had abundant evidence of this in the form of obviously well-used nesting sites containing moulted nestling plumage, feather "scales" and, in several instances, egg-shell fragments. With the exception of the duck-occupied site, all other sites were within or adjacent to known colonies of Sooty Shearwaters. This was not surprising considering that the necessary nesting habitat and site characteristics were anticipated to be similar for each species.

There was none of the usual evidence such as dead bird remains left by cats or skuas to indicate the return of this species to the island. The lack of remains of dead birds away from the immediate proximity of burrows, does implicate cats in particular and not skuas as the determinant of this species' fate since skuas preying on White-headed Petrels and Grey Petrels from tussock-covered colonies would take the petrel to open terrain, away from the colony. Also, based on the indications of cat abundance over time (Copson 2002), Grey Petrels may have had little chance to breed successfully until 1997 or 1998

Grey Petrels have continued breeding in at least some of the 1999 burrows that fledged chicks in 2000 (DPIWE unpublished records) and additional burrows as well as new breeding sites have been subsequently found (Schulz et al. 2005).

\section{Cape Petrel, Daption capense (Linnaeus, 1758)}

Despite Cape Petrels being seen regularly offshore and occasionally feeding on seal carcasses at the shoreline, the only observations of this species ashore anywhere in the region were small numbers at Anchor Rock nearly $1 \mathrm{~km}$ to the northwest of the island's northern end and on Gorilla Rock which was visited regularly by up to six birds in late October 1979. The opportunity to determine the breeding status of this species at these relatively inaccessible localities did not arise. It was immediately adjacent to Gorilla Rock, only several hundred metres off the east side of the island's northern end, that a pair was first reported occupying a suitable nest ledge in mid- to late October 1999 (A. Rooke pers. comm.). However, it was not until 2002 that the first breeding attempt on the island was recorded at this site (Threatened Species Section 2007).

\section{Soft-plumaged Petrel, Pterodroma mollis (Gould, 1844)}

By late 1999, despite additional evidence to that reported in Brothers (1984), breeding of Soft-plumaged Petrels had not been confirmed and there were seven more records of cat- or skua-killed adult birds, two of these at locations where birds had previously been found dead (indicated in table 8). At two localities, burrows believed to be those of Soft-plumaged Petrels were found near dead bird remains with all three burrows being empty, although two contained freshly-collected nesting material (i.e., vegetation). These burrows and most remains of dead birds were found in the vicinity of Sooty Shearwater colonies. This added to the difficulty of confirming whether this species was breeding on Macquarie Island. Although further observations have been made since 1999 , breeding was not confirmed until the 2006 breeding season (Bryant \& Shaw 2007). The records of Soft-plumaged Petrels seen ashore in July at Macquarie Island (Threatened Species Section 2007) adds weight to the argument (Brothers 1984) that such timing of visitation would have made them particularly vulnerable to predators, therefore increasing the likelihood that recent records are indications of yet another petrel species recovering here, rather than newly establishing.

\section{Blue Petrel, Halobaena caerulea (J.F. Gmelin, 1789)}

Prior to 1999, all searches of colonies for Blue Petrels, including that of Brothers (1984), indicated that there was little or no prospect of a successful outcome from breeding attempts. For example, at the Hurd Point colony in November 1988 only one incubating adult was found aside from three fresh-killed, partly-eaten birds. In November 1993 out of 31 burrows, only four contained an adult incubating, two had a pair of birds without an egg and the remainder were empty, four of these with chewed eggs at entrances. There was also extensive damage to tussock and Cotula plumosa Hook. f. by rats. At Douglas Point in November 1988, incubating birds were readily located despite abundant evidence of rats. However, by early December 1993 there were partly-eaten eggs and chick carcasses on the surface of the colony and only three birds brooding new chicks in the 15 nests that it was possible to check. At Green Gorge colony in late November 1993, nest sites were unoccupied, and there was no sign of rats, which is usual only at this colony. Therefore the four abandoned eggs found here had remained uneaten.

In 1988 the Langdon Point Blue Petrel colony did not have the usual skua territory adjacent to it and remains of only five petrels were found here whereas in 1993 there were the remains of 34 petrels. The colony was not visited in 1993 due to rough seas. In 1988 it was typically rat-damaged, but in 1999 there was no evidence of rats being present. As a consequence, on 26 January 2000, for the first time, there were indications that Blue Petrel chicks were being reared successfully. One burrow contained a full-grown chick with only a small amount of down remaining at the nape of its neck. There were also seven burrows, excavated by skuas, that had contained similarly advanced chicks. However, at other breeding colonies when visited between early December and late January there were abundant signs of rats but no recent petrel activity.

To explain why the Langdon Point colony had no rats in 1999, meteorological data in preceding years were examined. These revealed a prolonged, severe cold period in 1995, the severity of which had not occurred since records began in April 1948. In late July 1995 there was the most persistently cold week ever recorded with nine consecutive days averaging below $0^{\circ} \mathrm{C}$. This month was also the coldest calendar month and had the coldest day $\left(-4.8^{\circ} \mathrm{C}\right)$ on record. The combination of low Blue Petrel abundance in July (Brothers 1984) and the dominant plant species being scarce here for both rat protection and food would have increased the vulnerability of rats present. While rats may have been eliminated from all other Blue Petrel colonies by the same event, the Langdon Point colony was the only site without rats four breeding seasons later, probably due to the exposed rock and expanses of water which rats need to negotiate to repopulate the area. Green Gorge colony, situated on a rock 
TABLE 5

Locality details, burrow counts and habitat condition for Sooty Shearwater colonies on Macquarie Island between 1975 and 1999

\begin{tabular}{|c|c|c|c|c|c|c|c|c|c|c|c|c|c|c|c|c|}
\hline \multirow{3}{*}{ Colony location } & \multirow{3}{*}{$\begin{array}{l}\text { Locality } \\
\text { grid ref }\end{array}$} & \multicolumn{4}{|c|}{ Year 1975-1979 } & \multicolumn{4}{|c|}{ Year 1988} & \multicolumn{3}{|c|}{ Year 1993} & \multicolumn{4}{|c|}{ Year 1999} \\
\hline & & \multirow{2}{*}{$\begin{array}{l}\text { Burrow } \\
\text { count }\end{array}$} & \multicolumn{3}{|c|}{ Rabbit damage } & \multirow{2}{*}{$\begin{array}{c}\text { Burrow } \\
\text { count }\end{array}$} & \multicolumn{3}{|c|}{ Rabbit damage } & \multirow{2}{*}{$\begin{array}{c}\text { Burrow } \\
\text { count }\end{array}$} & \multicolumn{2}{|r|}{ Rabbit damage } & \multirow{2}{*}{$\begin{array}{c}\text { Burrow } \\
\text { count }\end{array}$} & \multicolumn{3}{|c|}{ Rabbit damage } \\
\hline & & & none & past & current activity & & none & $\begin{array}{l}\text { since } \\
1979\end{array}$ & current activity & & none & $\begin{array}{l}\text { since current activity } \\
1988\end{array}$ & & none & $\begin{array}{l}\text { since } \\
1993\end{array}$ & $\begin{array}{l}\text { current } \\
\text { activity }\end{array}$ \\
\hline North Head & 116617 & 20 & $\sqrt{ }$ & & & & & & & 0 & $\sqrt{ }$ & & 0 & $\sqrt{ }$ & & \\
\hline North Head & 113617 & & & & & & & & & 10 & $\sqrt{ }$ & & 6 & $\checkmark$ & & \\
\hline North Head & 116619 & 20 & $\sqrt{ }$ & & & & & & & 0 & $\checkmark$ & & 0 & $\sqrt{ }$ & & \\
\hline North Head & 114619 & 10 & $\sqrt{ }$ & & & 0 & & & Severe & 0 & $\checkmark$ & & 0 & $\checkmark$ & & \\
\hline North Head & 113625 & 10 & $\downarrow$ & & & 0 & & & Severe & 0 & $\sqrt{ }$ & & 0 & $\checkmark$ & & \\
\hline North Head & 113626 & 10 & $\checkmark$ & & & 13 & & & Mod & 16 & $\checkmark$ & & 14 & $\checkmark$ & & \\
\hline North Head & 114627 & 10 & $\sqrt{ }$ & & & 4 & & & Mod & 10 & $\checkmark$ & & 8 & $\checkmark$ & & \\
\hline North Head & 115624 & 10 & $\checkmark$ & & & 0 & & & Severe & 0 & $\sqrt{ }$ & & 0 & $\sqrt{ }$ & & \\
\hline North Head & 116623 & 20 & $\checkmark$ & & & 3 & & & Severe & 4 & $\checkmark$ & & 0 & $\checkmark$ & & \\
\hline North Head & 116620 & 20 & $\checkmark$ & & & 14 & & & Mod & 18 & $\checkmark$ & & 0 & $\checkmark$ & & \\
\hline Perseverance Bluff & 101604 & & & & & & & & & & & & $2^{2}$ & & & Light \\
\hline Gadget Gully & 107602 & 23 & $\sqrt{ }$ & & & 9 & & & Light & 10 & $\checkmark$ & & 9 & $\sqrt{ }$ & & Mod \\
\hline Halfway Hill (4) ${ }^{1}$ & 109596 & & & & & & & & & 36 & $\checkmark$ & & 30 & & & Severe \\
\hline Halfway Hill South & 109593 & & & & & & & & & 11 & $\checkmark$ & & 19 & & & Severe \\
\hline Sandy Bay North & 102558 & & & & & & & & & & & & $7^{2}$ & & & Light \\
\hline Sandy Hut (3) & 098546 & 49 & & & Severe & 8 & & & Mod & 17 & $\sqrt{ }$ & & 19 & & & Severe \\
\hline Sandy Bay South & 097543 & & & & & & & & & & & & $8^{2}$ & & & Light \\
\hline Brothers Point (8) & 100525 & 20 & $\checkmark$ & & & 4 & $\checkmark$ & & & & $\checkmark$ & & 20 & $\sqrt{ }$ & & \\
\hline Brothers Point & 100526 & 40 & $\checkmark$ & & & 36 & $\checkmark$ & & & & $\checkmark$ & & 19 & $\sqrt{ }$ & & \\
\hline Brothers Point & 100527 & 30 & $\checkmark$ & & & 9 & $\checkmark$ & & & & $\sqrt{ }$ & & 15 & $\sqrt{ }$ & & \\
\hline Brothers Point Trig & 103523 & & & & & 22 & $\checkmark$ & & & 18 & $\sqrt{ }$ & & 17 & & & Light \\
\hline Brothers Point -all 8 sites & & 90 & & & & & & & & 78 & & & 82 & & & \\
\hline Green Gorge & 087462 & 36 & $\sqrt{ }$ & & & 18 & & & Light & 29 & $\sqrt{ }$ & & 35 & & & Mod \\
\hline Green Gorge South (2) & 085452 & & & & & & & & & 7 & $\sqrt{ }$ & & 11 & & & Severe \\
\hline Saddle Point (2) & 076426 & 5 & & & Severe & & & & & 2 & $\checkmark$ & & 0 & & & Severe \\
\hline Saddle Point & 076427 & 19 & $\checkmark$ & & & & & & & & $\checkmark$ & & 8 & & & Severe \\
\hline Saddle Point & 078428 & 20 & $\checkmark$ & & & & & & & & $\sqrt{ }$ & & 18 & & & Severe \\
\hline Saddle Point & 078444 & 7 & $\checkmark$ & & & & & & & 7 & $\checkmark$ & & 11 & & & Severe \\
\hline Saddle Point & 086457 & 13 & $\checkmark$ & & & & & & & & $\sqrt{ }$ & & 0 & & & Severe \\
\hline Lusitania North & 059389 & & & & & & & & & & & & $4^{2}$ & $\sqrt{ }$ & & \\
\hline Lusitania North & 058387 & & & & & & & & & & & & $8^{2}$ & $\checkmark$ & & \\
\hline Lusitania North & 053370 & & & & & & & & & & & & 14 & $\checkmark$ & & Light \\
\hline
\end{tabular}




\begin{tabular}{|c|c|c|c|c|c|c|c|c|c|c|c|c|c|c|c|}
\hline Lusitania Hut & 054366 & 50 & $\checkmark$ & & & 13 & & & Severe & 44 & $\sqrt{ }$ & & 38 & $\sqrt{ }$ & \\
\hline Mt Jeffries & 055355 & & & & & & & & & 1 & & Light & 0 & $\sqrt{ }$ & \\
\hline Mt Jeffries & 055346 & & & & & & & & & 13 & & Light & 18 & $\sqrt{ }$ & \\
\hline Mt Jeffries & 054346 & & & & & & & & & 7 & & Light & 6 & $\sqrt{ }$ & \\
\hline Mt Jeffries & 054345 & & & & & & & & & 3 & & Light & 5 & $\checkmark$ & \\
\hline Mt Jeffries & 050336 & & & & & & & & & & & & $13^{2}$ & & Severe \\
\hline Hurd Scree East (3) & 043314 & 20 & & & Severe & & & & & & $\sqrt{ }$ & & 36 & & Severe \\
\hline Hurd Scree West & 036311 & 10 & $\sqrt{ }$ & & & & & & & 19 & & Severe & 11 & & Severe \\
\hline South Coast East & 027312 & 60 & & & Severe & 22 & & & Severe & 47 & $\sqrt{ }$ & & 18 & & Severe \\
\hline South Coast West & 024312 & 500 & & & Little & 100 & & & Severe & 79 & & Severe & 53 & & Severe \\
\hline S. W. Point & 012317 & 24 & $\sqrt{ }$ & & & 26 & $\checkmark$ & & & 16 & $\sqrt{ }$ & & 12 & $\checkmark$ & \\
\hline Petrel Peak & 013319 & & & & & & & & & & & & $7^{2}$ & $\checkmark$ & \\
\hline Sodomy West (3) & 020328 & 100 & $\sqrt{ }$ & & & & & & & 14 & $\sqrt{ }$ & & 39 & & Severe \\
\hline Cape Star (2) & 017341 & 100 & $\sqrt{ }$ & & & 35 & & & Severe & 27 & $\sqrt{ }$ & & 30 & & Severe \\
\hline Precarious Point (3) & 024356 & 48 & $\sqrt{ }$ & & & & & & & 41 & & Severe & 88 & $\checkmark$ & \\
\hline Precarious North & 028367 & & & & & & & & & & & & 1 & & Severe \\
\hline Rockhopper Point & 026395 & 10 & $\checkmark$ & & & & & & & 14 & $\sqrt{ }$ & & 39 & & Severe \\
\hline Rockhopper North & 026396 & & & & & & & & & & & & 33 & $\checkmark$ & \\
\hline Cape Toutcher (3) & 029406 & & & & & & & & & & & & 46 & $\checkmark$ & \\
\hline Sandell & 044419 & & & & & & & & & & & & $7^{2}$ & & Light \\
\hline Mt Waite West (2) & 041458 & & & & & & & & & 30 & Mod & & 22 & & Mod \\
\hline Selleck Bay North (4) & 041472 & 25 & $\sqrt{ }$ & & & & & & & 30 & $\checkmark$ & & 34 & Severe & \\
\hline Skua Lake West (2) & 041479 & 23 & $\sqrt{ }$ & & & & & & & 11 & & Severe & 17 & Mod & \\
\hline South Soucek Bay (3) & 042478 & & & & & & & & & & & & 29 & & Severe \\
\hline Soucek Bay & 047486 & & & & & & & & & & & & 4 & & Severe \\
\hline Aurora Point Lower & 047496 & 100 & $\sqrt{ }$ & & & & & & & 6 & & Severe & 6 & Mod & \\
\hline Aurora Point Upper (3) & 047495 & 3 & & Severe & & 2 & & & Light & 0 & & Severe & 1 & $\checkmark$ & \\
\hline Cormorant Point (3) & 066529 & & & & & 4 & $\sqrt{ }$ & & & 6 & $\checkmark$ & & 19 & & Severe \\
\hline Flat Creek North & 065532 & & & & & & & & & & & & $4^{2}$ & $\checkmark$ & \\
\hline Mawson Point (2) & 06554.3 & 20 & $\checkmark$ & & & 12 & $\checkmark$ & & & 17 & $\checkmark$ & & 18 & & Light \\
\hline Bauer North (2) & 074564 & & & & & & & & & 5 & $\checkmark$ & & 21 & & Severe \\
\hline Langdon West & 065578 & 200 & $\checkmark$ & & & & & & & 28 & $\checkmark$ & & 26 & & Severe \\
\hline Langdon East & 070576 & $20^{2}$ & $\checkmark$ & & & 4 & & Severe & & 6 & $\sqrt{ }$ & & 14 & & Mod \\
\hline Handspike Corner (6) & 083612 & 91 & $\checkmark$ & & & 68 & & Severe & & 93 & $\checkmark$ & & 113 & & Light \\
\hline TOTALS & & 1806 & & & & 426 & & & & 830 & & & 1147 & & \\
\hline
\end{tabular}

1 Parentheses indicate number of separate burrow patches

${ }^{2}$ Newly established colony. 
TABLE 6

Sooty Shearwater population trends ${ }^{1}$ on Macquarie Island prior to 1979 and in 1999

\begin{tabular}{|c|c|c|c|c|c|}
\hline \multirow[b]{2}{*}{ Colony } & \multirow[b]{2}{*}{ Grid } & \multirow[b]{2}{*}{1979} & \multirow[b]{2}{*}{1999} & \multicolumn{2}{|c|}{ Count Difference } \\
\hline & & & & Up & Down \\
\hline$S W$ Point $^{2}$ & 012317 & 24 & 12 & & 12 \\
\hline Handspike Corner ${ }^{2}$ & 083612 & 91 & 113 & 22 & \\
\hline Precarious Point & 024356 & 48 & 88 & 40 & \\
\hline Gadget Gully ${ }^{2}$ & 107602 & 23 & 9 & & 14 \\
\hline Sellick Bay North & 041472 & 25 & 34 & 9 & \\
\hline Skua Lake West & 041479 & 23 & 17 & & 6 \\
\hline Aurora Pt upper ${ }^{2}$ & 047495 & 3 & 1 & & 2 \\
\hline Cape Star ${ }^{2}$ & 017341 & 100 & 30 & & 70 \\
\hline Mawson Point ${ }^{2}$ & 065543 & 20 & 18 & & 2 \\
\hline Brothers Point & 100524 & 90 & 82 & & 8 \\
\hline Langdon East ${ }^{2}$ & 070576 & 20 & 14 & & 6 \\
\hline \multirow[t]{7}{*}{ North Head } & 116620 & 20 & 0 & & 20 \\
\hline & 116623 & 20 & 0 & & 20 \\
\hline & 115624 & 10 & 0 & & 10 \\
\hline & 114627 & 10 & 8 & & 2 \\
\hline & 113626 & 10 & 14 & 4 & \\
\hline & 113625 & 10 & 0 & & 10 \\
\hline & 114619 & 10 & 8 & & 2 \\
\hline Green Gorge ${ }^{2}$ & 088462 & 36 & 35 & & 1 \\
\hline Lusitania Hut ${ }^{2}$ & 054366 & 50 & 38 & & 12 \\
\hline Sandy Hut ${ }^{2}$ & 098543 & 49 & 19 & & 30 \\
\hline Hurd Scree West & 036311 & 10 & 11 & 1 & \\
\hline Sodomy West & 020328 & 100 & 39 & & 61 \\
\hline Rockhopper Point & 026395 & 10 & 39 & 29 & \\
\hline \multirow[t]{4}{*}{ Saddle Point } & 076426 & 5 & 0 & & 5 \\
\hline & 076427 & 19 & 8 & & 11 \\
\hline & 076428 & 20 & 18 & & 2 \\
\hline & 078444 & 7 & 11 & 4 & \\
\hline Hurd Point East & 043314 & 20 & 36 & & 16 \\
\hline Total & & 883 & 702 & 109 & 259 \\
\hline
\end{tabular}

TABLE 7

Number of burrows, breeding evidence and site locality of Grey Petrels at Macquarie Island in 1993 and 1999

\begin{tabular}{lccccc}
\hline Site locality & Burrows with occupancy evidence & & \multicolumn{2}{c}{ Burrows from which chicks had fledged } \\
\cline { 2 - 3 } \cline { 5 - 6 } & 1993 & 1999 & & 1993 & 1999 \\
\hline Green Gorge 087462 & 8 & 2 & 0 & 0 \\
Green Gorge 088463 & 0 & 1 & 0 & 0 \\
Green Gorge Sth 085452 & 1 & 0 & 0 & - \\
Saddle Point 079434 & 1 & 2 & 0 & 0 \\
Brothers Point 103523 & 1 & 1 & 0 & 0 \\
Brothers Point 100524 & 0 & 3 & 0 & 2 \\
North Head 114618 & 0 & 2 & 0 & 1 \\
North Head 115627 & 0 & 1 & 0 & 0 \\
North Head 114627 & 0 & & 0 & 0 \\
\hline
\end{tabular}


TABIE 8

Observation details and locality of Soft-plumaged Petrel records on Macquarie Island between 1982 and 1999

\begin{tabular}{llcc}
\hline Date & \multicolumn{1}{c}{ Location } & Dead Adults & Burrows \\
\hline $03 / 11 / 93$ & Saddle Point 079428 & 1 & \\
$05 / 11 / 93$ & Hill 291 escarpment 033311 & 1 & 1 \\
$06 / 11 / 93$ & South Coast 027312 & 1 & 2 \\
$28 / 11 / 93$ & Brothers Point 103526 & 1 & \\
$01 / 12 / 93$ & Green Gorge 0884621 & 1 & \\
$02 / 12 / 93$ & Green Gorge 087465 & 1 & \\
$16 / 01 / 00$ & Sandell Bay 045422 & 1 & \\
\hline
\end{tabular}

1 Localities at which evidence of presence had also been found prior to 1982.

stack, although less distance offshore than the Langdon Point colony, provides another example of physical obstacles to rats. At Green Gorge colony the combination of the open pebble beach and water barrier is the probable explanation for this colony always having been rat-free. The rat-free status of the Green Gorge offshore colony probably explains why Blue Petrels' first attempt to recolonise mainland Macquarie Island was at this location. This new onshore colony at Green Gorge, containing approximately 20 burrows, was found in November 1999 on a low elevation spur, lightly covered with tussock and Stilbocarpa polaris (Hombr. \& Jacq.) A.Gray, with another smaller patch of burrows on a nearby slope. Although several eaten eggs and dead adults were present, one adult incubating an egg was also found out of ten burrows checked.

Weather-induced rat-free periods on offshore stacks may explain how Blue Petrels have survived despite little or no evidence of successful breeding in the past. Previously, an hypothesis for how this species managed to persist despite no evidence of successful breeding, was that numbers were being replaced from an unidentified colony on Bishop and Clerk islets, $33 \mathrm{~km}$ south of Macquarie Island (Brothers 1984). However, the survey there in 1993 (Brothers \& Ledingham 2008) did not locate this species. One colony known to exist that has not been visited is on a relatively large offshore stack in Caroline Bay (grid reference 017327) and is likely to be consistently rat-free. It may contain several hundred birds. Several Blue Petrels sighted over slopes at Macquarie Island's northern end in late November 1999, at 2230 hours, in an area where they had previously not been seen, indicate increased or more widespread activity by this species. A dead adult was found within a burrow in mid-January 2000 at South Double Point (grid reference 035444) amongst abundant sign of rats. Previously, the only evidence here of activity had been the cushion-forming plant Colobanthus muscoides Hook.f. that appeared to have once supported a network of interconnected burrows.

\section{Fairy Prion, Pachyptila turtur (Kuhl, 1820)}

Fairy Prion population recovery in response to vertebrate pest management was indicated in late November 1999 by an estimated 10-20 pairs recorded occupying rock and cliff caverns at the island's northernmost tip. Because the sites were inaccessible, breeding could not be confirmed, al though a large chick was subsequently seen at this location in 2001 (Threatened Species Section 2007). Also, on 12 December 1999, during call playback at Antarctic Prion burrows on the Prion Lake monitoring site, a Fairy Prion responded. The breeding status of this particular bird was not ascertained at the time, as this would have entailed unwarranted burrow excavation. These were the first and only indications of this species reoccupying Macquarie itself, although very small numbers have continued breeding since on offshore stacks (Brothers 1984) as well as several pairs breeding on Bishop and Clerk islets (Brothers \& Ledingham 2008). On Bishop and Clerk islets, with very scarce suitable habitat and strong inter-specific competition for alternative habitat, little opportunity exists for any increase in this population. On 25 November 1988, three eggs were being incubated at the offshore Langdon Point colony and it was here, on 26 January 2000 that one large down-covered chick was recorded. This is the first record of a Fairy Prion egg having hatched, and coincided with there being no rats at this locality for the first time.

\section{South Georgian Diving-Petrel, Pelecanoides georgicus Murphy \& Harper, 1916}

The only evidence of this species breeding on Macquarie Island itself was a fully-fledged chick amongst tussock at the southern end of the island on 23 December 1999. Apart from this record, only three burrows on Bishop and Clerk islets are known of in the region (Brothers \& Ledingham 2008).

\section{Common Diving-Petrel, Pelecanoides urinatrix (J.F. Gmelin, 1789)}

The burrows occupied by Common Diving-Petrels (Brothers 1984) were searched in the 1988 and 1999 breeding seasons but no birds were located. Burrow habitat was very fragile which limited the extent of searching, so it is inconclusive that none was present. The only record for the region of a hatched egg was in the one burrow that is on Bishop and Clerk islets (Brothers \& Ledingham 2008).

\section{Wilson's Storm-Petrel, Oceanites oceanicus (Kuhl, 1820)}

One burrow, possibly belonging to Wilson's Storm-Petrel, based on similarities with the three Wilson's Storm-Petrel burrows and surrounding habitat on Bishop and Clerk islets (Brothers \& Ledingham 2008) was found on 25 January 2000 . It was beneath $C$. muscoides on a very small offshore stack (Grid reference 101546) off Macquarie Island's east coast. The nest chamber contained one Black Rat, which, 
considering the limited area of the stack, can only have been a brief visitor there. No burrows were found at this locality in previous years.

\section{Vagrant Petrels}

Apart from the previously mentioned petrel species there were only three other species encountesed in the Macquarie Island region. The Southern Fulmar, Fulmarus glacialoides (A. Smith, 1840), Antarctic Petrel, Thalassoica antarctica (J.F. Gmelin, 1789) and Short-tailed Shearwater, Puffinus tenuirostris (Temminck, 1835), were all regularly encountered but only ever as beach-cast remains. When other petrel remains have been found it has been indicative of the species breeding on the island but this is not the case for these three. Likewise, only Snow Petrels, Pagodroma nivea (G. Forster, 1777), remains have been found (Scofield \& Wiltshire, 2004).

\section{Macquarie Shag Leucocarbo atriceps purpurascens Brandt, 1837}

Although not substantiated by diet studies of cats (Jones 1977) or Weka (Brothers \& Skira 1984), circumstantial evidence of regular cat and Weka activity in the vicinity of accessible Macquarie Shag colonies suggests that Macquarie Shags may be a food source for these introduced vertebrates. Such a locality and time-limited food source is not so readily detected with diet studies, unlike more widespread and constantly available prey. Macquarie Shag eggs and small chicks would have been relatively easy prey not only for Weka but for rats, and cats could possibly take small and large chicks but not adult shags.

Macquarie Shag colony count data (table 9) indicate that the number of breeding pairs fluctuates annually. The 1999 total of breeding pairs at predator-restricted access sites was similar (174) to the highest total in previous years of 167 based on all sites for which a count was made in each year. The same comparison for all open access colonies provides no clear evidence of a trend. Macquarie Shag populations are generally regulated by inundation of nests by high seas as well as by foraging restrictions caused by the islands' bathymetry and strong winds (Brothers 1985). The combined impact of these influences makes it impossible to accurately determine the impact that introduced predators may have had.

\section{Kelp Gull, Larus dominicanus M.H.K. Lichtenstein, 1823}

The most significant evidence of a reduction in introduced predator impact on Kelp Gulls was the first record of a nest containing two eggs found on a steep slope in tall tussock grassland habitat $50 \mathrm{~m}$ above sea level on 24 November 1999. Previously, all nests located were situated on elevated shoreline or offshore rocks where nests were either secure from, or more easily defended against, Weka, cats and also Great Skuas Stercorarius antarctica lonnbergi (Matthews, 1912). However, in these localities breeding attempts were often unsuccessful because of inundation by high seas. Also, although shoreline or offshore rock sites were more secure from Weka and cats, the opportunities for skua predation on gull eggs or chicks were greater at these sites than at nests with protective vegetation cover nearby. Considering the lack of access by cats to Kelp Gulls throughout the monitoring period, it is understandable that Kelp Gulls were seldom indicated as prey in the gut contents of cats $(0.2 \%$, or two occasions in 966 samples DPIWE unpublished data). It may be relevant that, although Weka had been eradicated for ten years, it was not until all but the last few cats had been eliminated, that gulls were known to have made an attempt at nesting in a high predator-risk location.

Counts indicate thar there has been little or no change to the distribution and abundance of this species over time. The highest count ever of birds in first-year plumage was made on 25 January 2000 when 35 were seen together in a flock with 26 birds in second-year to pre-adult plumage. While this flock may not have contained every bird on the island from these age classes, it is considered indicative of the small population and low fledgling success of Kelp Gulls on Macquarie Island.

In 1999, a comprehensive whole island census recorded 135 nests with similar numbers on east ( 69 pairs) and west (66 pairs) coasts. At every site there was only one nest but this was often defended by a number of Kelp Gulls against intrusion. It is possible that, such nesting behaviour became a necessity in response to Weka and cats and, as a result, the number of gulls declined as a consequence of lower breeding success. It remains to be seen whether Kelp Gulls will respond to cat and Weka eradication by nesting in greater abundance in larger colonies or simply continue using widely scattered locations in the traditionally more secure sites offshore, both ultimately leading to an increase in abundance of this species.

\section{Antarctic Tern, Sterna vittata bethunei Buller, 1896}

Records of observations made during visits to the island between 1975 and 2000 indicated that Antarctic Terns breed annually at regular sites, in very low and variable numbers, with most breeding attempts failing to produce a fledgling. Eggs are laid from early November to mid-January at widely scattered localities. Antarctic Terns nest on inaccessible offshore stacks with a proportion of non-breeding birds also in attendance, both factors making reliable counts difficult. Breeding attempts were noted to be often unsuccessful in early incubation, possibly due to Great Skua and Kelp Gull predation, and fledglings were noted to be present in a colony simultaneously with as yet unhatched eggs. In general though, breeding was often unsuccessful due to nesting sites being vulnerable to high seas.

Pairs often nested in isolation, although up to five nests were encountered at a site. The very limited, apparently preferred feeding habitat in relatively calm, shallow waters such as inshore reef-protected areas of Sandell Bay and in the region between Langdon Bay and Eagle Bay does not exist anywhere else around the island. It is adjacent to these feeding localities that groups of nesting birds occur. However, along the islands' comparatively sheltered east coast, there are fewer and smaller similar feeding environments, and only isolated pairs occur there. Of 11 known breeding sites six are on the west coast, five on the east coast, and the highest count in any year was in 1999 with 19 pairs nesting. No more than four fledglings have been seen in any year. Terns, like Kelp Gulls, are likely to have been greatly affected first directly and then indirectly by introduced predators. However, they may benefit little from the eradication of cats and Weka because rats continue to pose a threat sufficient to discourage terns from nesting at sites more secure from destruction by high seas (Schulz $\&$ Gales 2004). Even nesting sites just offshore, with 
inadequate habitat for rats, are visited by rats. Therefore, in a number of nesting locations, if high seas do not kill chicks or eggs, rats do. At three sites vulnerable to high seas no fledglings were produced in any of the six breeding seasons of records between 1975 and 1999 (although in two of these seasons no breeding attempt occurred or was so brief as to go undetected).

A 2003 census of 24 pairs (Schulz \& Gales 2004) appears not to be related to the number of nests present and, considering the incomplete nature of all counts, it is difficult to identify any population trend. It is likely that the suspected limited foraging habitat will limit population increase therefore making it difficult to be able to draw conclusions about any relationship between tern populations and vertebrate pest management.

\section{Great Skua, Stercorarius antarctica lonnbergi (Matthews, 1912)}

Rabbits have had a major influence on the distribution (Skira 1984) and probably also abundance of Great Skuas even though limited specific data were obtained for this species between 1975 and 1999. Skuas seem to be the only indigenous species that has benefited from any of the vertebrate pests. Prior to the introduction of Myxoma virus to control rabbits in 1978 a significanr portion of skua breeding coincided with areas of high rabbit abundance, particularly on the plateau, because rabbits (especially young ones) were a major prey item of skuas (Jones \& Skira 1979). The correlation of greater skua abundance with a large rabbit population was supported by the considerable decline in the incidence of skuas rearing two chicks and decrease in overall skua breeding success when rabbit numbers were lowest, as observed in 1988 (Copson 2004).

Skua dependence on rabbits as a food source could have resulted in reduced predation on petrels. However, it was because of rabbits that skuas became more widely distributed throughout petrel nesting localities, and this in turn exposed more petrels to possible skua predation. Following the introduction of Myxoma virus, skua nesting became more closely aligned with food sources such as penguin colonies, and there was a noticeable decline in skua-killed petrel remains. It is possible that the abundance of rabbit kittens, hunted by skuas mostly in daytime, may have made the largely-nocturnal activity of petrel hunting unnecessary. In 1999, skuas had a greater impact than in other breeding seasons on certain indigenous species (e.g., one Southern Giant-Petrel, Macronectes giganteus (J.F. Gmelin, 1789) colony alone, had 33 eggs taken by skuas from 80 nests). As a result of pest management actions, there may be readjustments between indigenous species that do not necessarily result in greater abundance for each of those species.

If skuas, particularly their chicks, had been vulnerable, as one would expect, to cat predation, then the skua population would have been decimated. Jones (1977) indicates that skuas are not vulnerable to cat predation, and even during the time interval when there was least availability of rabbits as prey for cats, there was no evidence from examination of cat diet studies that skuas were eaten ( $G$. Copson pers. comm.) It is likely that skuas will have increased predator impact above natural rates of predation on indigenous species, during periods of readjustment in skua breeding distribution and abundance as a response to changes in rabbit abundance. Therefore, keeping rabbit numbers as low as possible, prior to an eradication attempt is important. The serious impact on petrels as a consequence of petrel colony habitat destruction from rabbit grazing is far more detrimental to petrels than any increased skua predation predicted to occur during the process of rabbit eradication.

\section{Impacts of changing rainfall patterns on burrow-nesting petrels}

Since 1988, there has been an impression of brief but heavier rainfall events in comparison with previous constant, but more continuous, light precipitation. The following observations are believed to be a result of variations in the daily rainfall pattern:

- from 1988 onward, petrel colonies in tussock habitat were becoming increasingly conspicuous, as surrounding vegetation attained a drier, sparser appearance contrasting with the usual lush, green petrel colony vegetation. In recent years this trend has given the island a more yellowbrown, rather than yellow-green overall appearance;

- by 1999, gully erosion of walking track sections had become apparent and, rather than being associated with any increase in track usage (Dixon 2001), appeared to result from heavier rainfall occurring in shorter periods of time;

- in 1999, mud-beds in certain temporary lakes or tarns were observed undergoing periods of drying-induced cracking for the first time; and

- by 1993 , and especially so by 1999 , rabbits appeared to be favouring steep and therefore better-drained coastal slopes. There appeared to be a greater frequency of burrow flooding in other sites.

In observations of seven petrel burrow flooding events the least amount of rainfall to cause flooding was $6.4 \mathrm{~mm}$ over the preceding 24-hour period. The relationship between burrow flooding and the rainfall that occurred prior to the 24-hour period immediately before the flooding event was not determined. However, the relationship between a specific amount of precipitation and burrow flooding may be complicated by a prolonged dry or wet interval occurring more than 24 hours before burrow flooding (table 10). This may mean that the average of $13.4 \mathrm{~mm}$ of rain in the 24 hours preceding the seven flood events reported here is indicative of the amount of rainfall required to flood burrows. Water table levels in response to rainfall (tables $10,11,12)$ also indicate that when approximately $13 \mathrm{~mm}$ of rainfall falls within a 24 -hour period, water table rise was sufficient to inundate burrows (table 12). However, when only $5 \mathrm{~mm}$ of rain fell, burrows were not inundated and the water table fell. Unfortunately no data were obtained for water table response to rainfall between $5 \mathrm{~mm}$ and $13 \mathrm{~mm}$ in a 24 -hour period to ascertain a more accurate relationship. In addition, because burrow flooding may have commenced prior to monitoring, the amount of rainfall responsible for inundation of burrows is probably less than the average of $13.4 \mathrm{~mm}$ derived from weather station records.

The seven burrow flooding events were correlated with the rainfall records at the station. However, there can be significant differences between rainfall at different localities on the island (table 13), such as with increasing altitude where weather conditions can be cooler, windier and wetter (Tweedie 2000). Over a 244-day period, there was a $16 \%$ difference in total rainfall recorded at Green Gorge (507.5 $\mathrm{mm})$ and the station $(601.2 \mathrm{~mm})$. However, over shorter time intervals there can be more significant differences in 
TABLE 9

The number of Macquarie Shag breeding pairs at Macquarie Island between 1979 and 1999

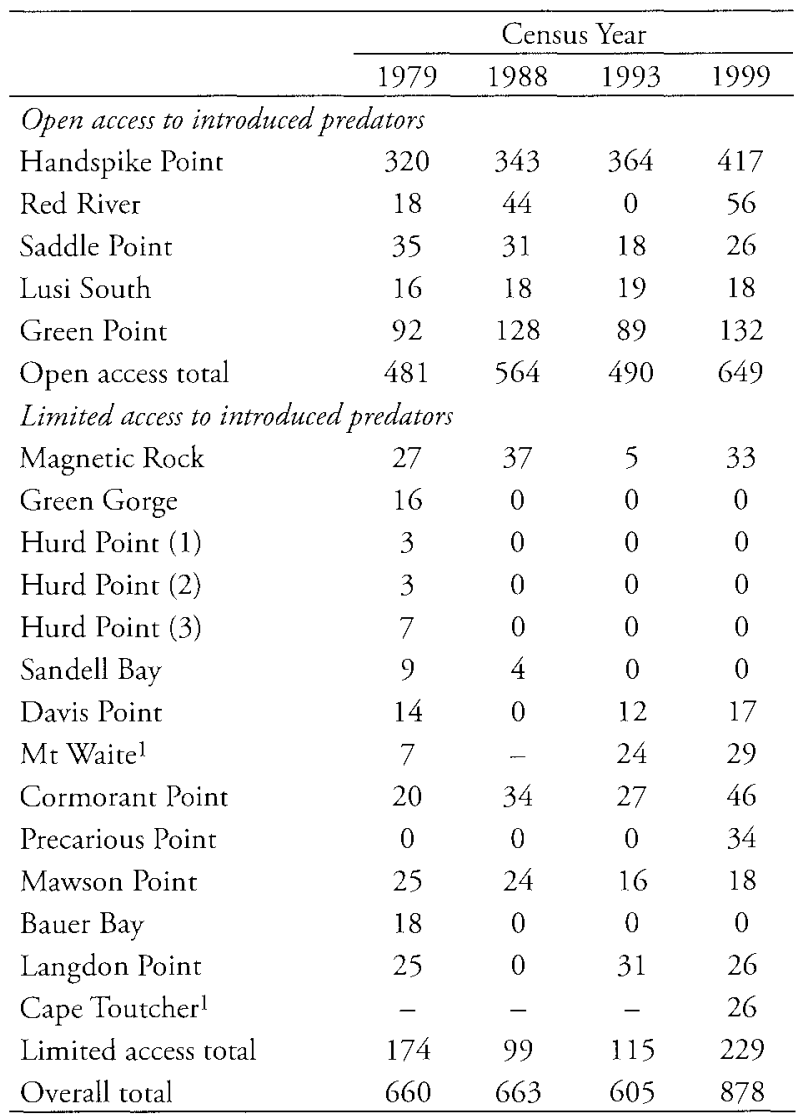

${ }^{1}$ Dash indicates colony not visited. Bishop and Clerk islets colony excluded.
TABLE 10

Changes in water table level ${ }^{1}$ in typical prion and rabbit burrowing habitat on Macquarie Island

\begin{tabular}{|c|c|c|c|c|c|c|c|c|c|}
\hline \multirow[b]{3}{*}{ Site } & \multirow[b]{3}{*}{ Hole } & \multicolumn{8}{|c|}{ Rainfall (mm) in preceding $24-\mathrm{hr}$ period } \\
\hline & & \multicolumn{2}{|c|}{$0^{2}$} & \multicolumn{2}{|c|}{$<1$} & \multicolumn{2}{|c|}{5} & \multicolumn{2}{|c|}{13} \\
\hline & & $A^{3}$ & B & A & B & A & B & A & $\mathrm{B}$ \\
\hline \multirow[t]{3}{*}{1} & 1 & $37^{4}$ & $50+$ & $50+$ & $50+$ & 31 & $50+$ & $50+$ & 36 \\
\hline & 2 & 50 & $50+$ & $50+$ & $50+$ & $50+$ & $50+$ & $50+$ & 50 \\
\hline & 3 & 0 & 0 & 1 & 4 & 0 & 0 & 3 & 0 \\
\hline \multirow[t]{3}{*}{2} & 1 & 39 & 36 & 22 & 24 & 15 & 19 & 33 & 27 \\
\hline & 2 & 24 & 15 & 21 & 25 & 0 & 11 & 11 & 11 \\
\hline & 3 & 41 & 44 & 38 & 42 & 38 & 40 & 50 & 50 \\
\hline \multirow[t]{3}{*}{3} & 1 & 0 & 7 & 6 & 7 & 0 & 7 & 9 & 0 \\
\hline & 2 & 0 & 8 & 8 & 14 & 0 & 4 & 15 & 0 \\
\hline & 3 & 6 & 12 & 15 & 19 & 0 & 10 & 19 & 9 \\
\hline \multirow[t]{3}{*}{4} & 1 & 3 & 20 & 19 & 20 & 0 & 10 & 25 & 15 \\
\hline & 2 & $50_{+}$ & $50_{+}$ & $50+$ & $50+$ & $50+$ & $50+$ & $50+$ & $50_{+}$ \\
\hline & 3 & $50+$ & $50+$ & $50+$ & $50+$ & 41 & $50+$ & $50+$ & $50+$ \\
\hline \multirow[t]{3}{*}{5} & 1 & 16 & 24 & 30 & 30 & 9 & 25 & 27 & 11 \\
\hline & 2 & 45 & 33 & 34 & 39 & 19 & 28 & 36 & 36 \\
\hline & 3 & 50 & $50+$ & 47 & 48 & 28 & $50+$ & $50+$ & $50+$ \\
\hline \multirow[t]{3}{*}{6} & 1 & $50+$ & $50+$ & $50+$ & $50+$ & $50+$ & $50+$ & $50+$ & $50+$ \\
\hline & 2 & $50+$ & $50+$ & $50+$ & $50+$ & 30 & $50+$ & $50+$ & 40 \\
\hline & 3 & $50+$ & $50+$ & $50+$ & $50+$ & 47 & $50+$ & $50+$ & 44 \\
\hline \multirow[t]{3}{*}{7} & 1 & 36 & 50 & $50+$ & 29 & 26 & $50+$ & $50+$ & 31 \\
\hline & 2 & 15 & 24 & 25 & $50_{+}$ & 0 & 24 & 27 & 16 \\
\hline & 3 & 50 & $50+$ & $50+$ & $50+$ & 30 & 35 & $50+$ & 43 \\
\hline \multirow[t]{3}{*}{8} & 1 & 9 & 24 & 24 & 24 & 7 & 22 & 28 & 15 \\
\hline & 2 & 50 & 38 & 42 & $50+$ & 16 & 32 & $50+$ & $50+$ \\
\hline & 3 & $50+$ & $50+$ & $50+$ & $50+$ & $50+$ & $50+$ & $50+$ & $50+$ \\
\hline
\end{tabular}

${ }^{1}$ In response to varying amounts of rainfall in the preceding 24 hour period.

2 Rainfall categories: $<1 \mathrm{~mm}-$ insufficient to cause burrow flooding, $5 \mathrm{~mm}$ - possible flooding, $13 \mathrm{~mm}$ or more - flooding likely.

3 Water levels at: A - start observation period; B - end 12-hr observation period.

$40 \mathrm{~cm}$ - surface, $50 \mathrm{~cm}$ - maximum depth reading. Water levels below this depth are shown as $50+$.

TABLE 11

Water table fluctuations

\begin{tabular}{llcccc}
\hline Water table & & \multicolumn{3}{c}{ Amount of rainfall $(\mathrm{mm})$ in preceding $24 \mathrm{hr}^{1}$} \\
\cline { 3 - 6 } level change & & 0 & $<1$ & 5 & 13 \\
\hline Increase & number of records & 4 & 0 & 0 & 9 \\
& average amount $(\mathrm{cm})$ & 9 & - & - & 10.3 \\
\multirow{2}{*}{ Decrease } & range $(\mathrm{cm})$ & $3-12$ & - & - & $3-16$ \\
& number of records & 9 & 10 & 12 & 0 \\
\multirow{4}{*}{ Stable } & average amount $(\mathrm{cm})$ & 9.7 & 3.1 & 9.8 & - \\
Indeterminate & range $(\mathrm{cm})$ & $3-17$ & $1-6$ & $2-24$ & - \\
& number of records & 1 & 2 & 1 & 3 \\
& number of records & 10 & 12 & 11 & 12 \\
& all records & 24 & 24 & 24 & 24 \\
\hline
\end{tabular}

${ }^{1}$ Derived from table 10. 
TABLE 12

Water table level ${ }^{1}$ response to rainfall over a 24-hour period

\begin{tabular}{lcccc}
\hline Number of occasions of & \multicolumn{4}{c}{ Rainfall (mm) } \\
\cline { 2 - 5 } water table level status & 0 & $<1$ & 5 & 13 \\
\hline remained above $15 \mathrm{~cm}$ only & 4 & 3 & 6 & 4 \\
remained above $25 \mathrm{~cm}$ only & 9 & 8 & 10 & 6 \\
remained below $15 \mathrm{~cm}$ only & 16 & 20 & 14 & 16 \\
remained below $25 \mathrm{~cm}$ only & 15 & 15 & 11 & 15 \\
increased to above $15 \mathrm{~cm}$ only & 1 & 0 & 0 & 4 \\
increased to above $25 \mathrm{~cm}$ & 0 & 0 & 0 & 3 \\
decreased to below $15 \mathrm{~cm}$ & 3 & 1 & 4 & 0 \\
decreased to below $25 \mathrm{~cm}$ & 0 & 1 & 3 & 0 \\
\hline
\end{tabular}

1 In relation to a depth at which smaller perrel burrows may be flooded $(15 \mathrm{~cm})$ and to a depth at which rabbit and larger petrel burrows may be flooded $(25 \mathrm{~cm})$ based on water level measurements of three holes at eight sites (from table 10).

rainfall (table 13) between these two localities, although they are only $15 \mathrm{~km}$ apart on the east coast (fig. 1). For example, over a 15-day period in May 1976, $18 \mathrm{~mm}$ of rain fell at Green Gorge but $60.6 \mathrm{~mm}$ fell at the station, and in four days in October 1976 Green Gorge had $20 \mathrm{~mm}$ whereas the station had only $13 \mathrm{~mm}$. In 19 corresponding 24-hour rainfall records available from both localities the maximum discrepancy was $3 \mathrm{~mm}$ with a total of $10 \mathrm{~mm}$ difference over the 19 days. However, the station rainfall records corresponded with each burrow flooding event observed, irrespective of where on the island this had occurred.

If the minimum amount of rainfall required to cause burrow flooding is actually about $6 \mathrm{~mm}$ in the preceding 24-hour period, then, on average, this will occur four times per month. However, the frequency of $6 \mathrm{~mm}$ or more of rain falling within a 24-hour period is increasing. The frequency of 24-hour periods within which $12 \mathrm{~mm}$ or more of rain falls has also increased. While the total annual rainfall figures for the years between 1968 and 2006 indicate a general increase (fig. 2), it would appear that the greatest contribution to this is from the amount and frequency of higher rainfall quantities within any 24-hour period (table 14). When daily rainfall is divided into four categories: days of no rain, days with insufficient rainfall to cause burrow flooding $(0.2-5.9 \mathrm{~mm})$, days where burrow flooding may occur $(6-11.9 \mathrm{~mm})$ and days when burrow flooding is most likely to occur (>12 $\mathrm{mm}$ ), the possibility of burrow flooding occurring happens with greater regularity. In addition, the likelihood of burrow flooding is aggravated by an increasing trend of consecutive heavy rain days sufficient to cause flooding (table 15, fig. 3).

A division of the 1968-2006 period into nine-year intervals (1971-2006) indicates an apparent increasing trend for both $6-11.9 \mathrm{~mm}$ and $>12 \mathrm{~mm}$ of daily rainfall events, but no clear trend for the $0.2-5.9 \mathrm{~mm}$ category (table 16). To ascertain which rainfall trend was likely to have the greatest impact on burrow flooding this same division of rainfall data was examined for two seasons, from November-April (greatest impact on breeding success due to burrow flooding) and from May-October (least impact
TABLE 13

Rainfall observation comparisons between $15 \mathrm{~km}$ distant localities on Macquarie Island over a total of 244 days in 1976

\begin{tabular}{|c|c|c|}
\hline $\begin{array}{l}\text { Observation period } \\
\text { (day/mth) }\end{array}$ & $\begin{array}{l}\text { Green Gorge } \\
\text { rainfall }(\mathrm{mm})\end{array}$ & $\begin{array}{c}\text { Station } \\
\text { rainfall }(\mathrm{mm})\end{array}$ \\
\hline $10 / 03-11 / 03$ & 5 & 6.8 \\
\hline $11 / 03-17 / 03$ & 7.5 & 13.6 \\
\hline $17 / 03-27 / 03$ & 35 & 46.6 \\
\hline $27 / 03-29 / 03$ & 2.5 & 0.4 \\
\hline $29 / 03-30 / 03$ & 10 & 7 \\
\hline $30 / 03-17 / 04$ & 55 & 71.2 \\
\hline $17 / 04-18 / 04$ & $<1$ & 1 \\
\hline $18 / 04-23 / 04$ & 11 & 10.6 \\
\hline $23 / 04-24 / 04$ & 2.5 & 4.8 \\
\hline $24 / 04-25 / 04$ & 1.5 & 3.2 \\
\hline $25 / 04-26 / 04$ & $<1$ & 3.4 \\
\hline $26 / 04-27 / 04$ & $<1$ & 1.4 \\
\hline $27 / 04-11 / 05$ & 75 & 63.6 \\
\hline $11 / 05-12 / 05$ & $<1$ & 1.8 \\
\hline $12 / 05-13 / 05$ & $<1$ & 2 \\
\hline $13 / 05-14 / 05$ & $<1$ & 1.4 \\
\hline $14 / 05-18 / 05$ & 10 & 12.8 \\
\hline $18 / 05-02 / 06$ & 18 & 60.6 \\
\hline $02 / 06-09 / 06$ & 25 & 26.8 \\
\hline $09 / 06-16 / 06$ & 25 & 15.8 \\
\hline $16 / 06-17 / 07$ & 28 & 70.6 \\
\hline $17 / 07-12 / 08$ & 32.5 & 34.4 \\
\hline $12 / 08-13 / 08$ & $<1$ & 1.6 \\
\hline $13 / 08-14 / 08$ & 0 & 0.2 \\
\hline $14 / 08-15 / 08$ & $<1$ & 0 \\
\hline $15 / 08-20 / 08$ & 12.5 & 10.6 \\
\hline $20 / 08-14 / 09$ & 27.5 & 17.6 \\
\hline $14 / 09-17 / 09$ & $<1$ & 3.6 \\
\hline $17 / 09-18 / 09$ & $<1$ & 0.4 \\
\hline $18 / 09-19 / 09$ & $<1$ & 2 \\
\hline $19 / 09-20 / 09$ & $<1$ & 1.4 \\
\hline $20 / 09-16 / 10$ & No data & 33.1 \\
\hline $16 / 10-17 / 10$ & $<1$ & 3.4 \\
\hline $17 / 10-18 / 10$ & $<1$ & 0.6 \\
\hline $18 / 10-19 / 10$ & 20 & 15 \\
\hline $19 / 10-22 / 10$ & 20 & 12.4 \\
\hline $22 / 10-06 / 11$ & 11 & 19.6 \\
\hline $06 / 11-07 / 11$ & $<1$ & 2.4 \\
\hline $07 / 11-04 / 12$ & 70 & 48 \\
\hline
\end{tabular}

on breeding success due to burrow flooding). While rainfall sufficient to cause burrow flooding (more than $6 \mathrm{~mm} / 24$ hours) has increased in both summer and winter, it is more pronounced (fig. 4) at a time when burrow flooding would have least impact on petrel breeding success. However, in the higher daily rainfall categories the number of days, as well as the quantity of rain, is increasing. The number of days with zero rainfall has declined (table 16, fig. 5) together with a decreasing frequency of consecutive zero rainfall days 
TABLE 14

Annual total rainfall on Macquarie Island between 1968 and 2006 showing the 24-hour amounts in three categories and this as a proportion of the total

\begin{tabular}{|c|c|c|c|c|c|c|c|}
\hline \multirow[t]{2}{*}{ Year } & \multirow{2}{*}{$\begin{array}{c}\text { Total } \\
\mathrm{mm}\end{array}$} & \multicolumn{2}{|c|}{$\begin{array}{c}0.2-5.9 \\
\mathrm{~mm} / 24 \mathrm{hrs}\end{array}$} & \multicolumn{2}{|c|}{$\begin{array}{c}6-11.9 \\
\mathrm{~mm} / 24 \mathrm{hrs}\end{array}$} & \multicolumn{2}{|c|}{$\begin{array}{c}12+ \\
\mathrm{mm} / 24 \mathrm{hrs}\end{array}$} \\
\hline & & $\mathrm{mm}$ & $\begin{array}{l}\% \text { of } \\
\text { total }\end{array}$ & $\mathrm{mm}$ & $\begin{array}{l}\% \text { of } \\
\text { total }\end{array}$ & $\mathrm{mm}$ & $\begin{array}{l}\% \text { of } \\
\text { total }\end{array}$ \\
\hline 1968 & 1079 & 544 & 50.4 & 297 & 27.4 & 238 & 22.1 \\
\hline 1969 & 944 & 484 & 51.3 & 212 & 22.5 & 248 & 26.3 \\
\hline 1970 & 818 & 506 & 61.9 & 187 & 22.9 & 125 & 15.3 \\
\hline 1971 & 789 & 395 & 50.1 & 220 & 27.9 & 174 & 22.1 \\
\hline 1972 & 820 & 505 & 61.6 & 256 & 31.2 & 59 & 7.2 \\
\hline 1973 & 766 & 350 & 61.3 & 106 & 22.7 & 311 & 16 \\
\hline 1974 & 827 & 446 & 53.9 & 191 & 23.1 & 190 & 23 \\
\hline 1975 & 900 & 490 & 54.4 & 272 & 30.2 & 138 & 15.3 \\
\hline 1976 & 941 & 462 & 49.1 & 261 & 27.7 & 218 & 23.2 \\
\hline 1977 & 946 & 514 & 54.3 & 274 & 29 & 158 & 16.7 \\
\hline 1978 & 1013 & 561 & 55.4 & 247 & 24.4 & 204 & 20.1 \\
\hline 1979 & 854 & 486 & 56.9 & 283 & 43.1 & 86 & 10.1 \\
\hline 1980 & 881 & 488 & 55.4 & 203 & 23 & 190 & 21.6 \\
\hline 1981 & 760 & 437 & 57.5 & 164 & 21.6 & 159 & 20.9 \\
\hline 1982 & 1055 & 496 & 40 & 360 & 34.1 & 198 & 18.8 \\
\hline 1983 & 1005 & 463 & 46.1 & 373 & 37.1 & 169 & 16.8 \\
\hline 1984 & 1028 & 508 & 49.4 & 266 & 25.9 & 254 & 24.7 \\
\hline 1985 & 823 & 439 & 53.3 & 254 & 30.9 & 130 & 15.8 \\
\hline 1986 & 955 & 524 & 54.9 & 249 & 26.1 & 182 & 19.1 \\
\hline 1987 & 931 & 531 & 57 & 258 & 27.7 & 142 & 15.3 \\
\hline 1988 & 1156 & 493 & 42.6 & 432 & 37.4 & 230 & 9.9 \\
\hline 1989 & 911 & 469 & 51.5 & 319 & 35 & 124 & 13.6 \\
\hline 1990 & 1079 & 518 & 48 & 346 & 32.1 & 215 & 19.9 \\
\hline 1991 & 1002 & 541 & 54 & 255 & 25.5 & 206 & 20.6 \\
\hline 1992 & 1113 & 495 & 44.5 & 376 & 33.8 & 242 & 21.7 \\
\hline 1993 & 1188 & 520 & 43.8 & 367 & 30.9 & 301 & 25.3 \\
\hline 1994 & 1080 & 535 & 49.5 & 264 & 24.4 & 281 & 26.1 \\
\hline 1995 & 1073 & 517 & 48.2 & 309 & 28.8 & 147 & 23 \\
\hline 1996 & 984 & 513 & 52.1 & 349 & 35.5 & 123 & 12.5 \\
\hline 1997 & 945 & 562 & 59.5 & 241 & 25.6 & 142 & 15 \\
\hline 1998 & 1067 & 530 & 49.7 & 381 & 35.7 & 157 & 14.7 \\
\hline 1999 & 1074 & 590 & 54.9 & 264 & 24.6 & 219 & 20.4 \\
\hline 2000 & 1189 & 576 & 48.4 & 390 & 32.8 & 223 & 18.8 \\
\hline 2001 & 1069 & 541 & 50.6 & 313 & 29.3 & 215 & 20.1 \\
\hline 2002 & 1023 & 514 & 50.2 & 285 & 26.7 & 224 & 21.9 \\
\hline 2003 & 1030 & 498 & 48.3 & 282 & 27.4 & 250 & 24.3 \\
\hline 2004 & 1009 & 455 & 45.1 & 322 & 31.9 & 232 & 23 \\
\hline 2005 & 1244 & 500 & 40.2 & 371 & 29.8 & 374 & 30.1 \\
\hline 2006 & 1094 & 569 & 52 & 310 & 28.3 & 215 & 19.7 \\
\hline
\end{tabular}

TABLE 15

The risk of increased burrow flooding from the frequency of consecutive 24-hour periods of $>6 \mathrm{~mm}$ rainfall between 1968 and 2006 on Macquarie Island

\begin{tabular}{|c|c|c|c|c|c|}
\hline \multirow[t]{2}{*}{ Year } & \multicolumn{4}{|c|}{ Number of consecutive days } & \multirow[t]{2}{*}{ Total } \\
\hline & 2 & 3 & 4 & 5 & \\
\hline 1968 & 4 & 1 & 0 & 0 & 5 \\
\hline 1969 & 5 & 0 & 0 & 0 & 5 \\
\hline 1970 & 2 & 0 & 0 & 0 & 2 \\
\hline 1971 & 0 & 0 & 0 & 0 & 0 \\
\hline 1972 & 2 & 1 & 0 & 0 & 3 \\
\hline 1973 & 2 & 1 & 0 & 0 & 3 \\
\hline 1974 & 2 & 0 & 0 & 0 & 2 \\
\hline 1975 & 2 & 2 & 0 & 0 & 4 \\
\hline 1976 & 4 & 1 & 0 & 0 & 5 \\
\hline 1977 & 4 & 0 & 0 & 0 & 4 \\
\hline 1978 & 1 & 1 & 0 & 0 & 2 \\
\hline 1979 & 1 & 0 & 0 & 0 & 1 \\
\hline 1980 & 1 & 0 & 0 & 0 & 1 \\
\hline 1981 & 2 & 0 & 0 & 0 & 2 \\
\hline 1982 & 3 & 2 & 0 & 0 & 5 \\
\hline 1983 & 7 & 1 & 0 & 0 & 8 \\
\hline 1984 & 5 & 1 & 0 & 0 & 6 \\
\hline 1985 & 0 & 0 & 0 & 0 & 0 \\
\hline 1986 & 7 & 2 & 0 & 0 & 9 \\
\hline 1987 & 4 & 0 & 0 & 0 & 4 \\
\hline 1988 & 10 & 0 & 0 & 0 & 10 \\
\hline 1989 & 6 & 1 & 0 & 1 & 8 \\
\hline 1990 & 4 & 3 & 0 & 0 & 7 \\
\hline 1991 & 7 & 0 & 0 & 0 & 7 \\
\hline 1992 & 7 & 1 & 0 & 0 & 8 \\
\hline 1993 & 6 & 0 & 0 & 0 & 6 \\
\hline 1994 & 2 & 1 & 0 & 0 & 3 \\
\hline 1995 & 6 & 1 & 0 & 0 & 7 \\
\hline 1996 & 5 & 2 & 0 & 0 & 7 \\
\hline 1997 & 3 & 0 & 0 & 0 & 3 \\
\hline 1998 & 3 & 1 & 0 & 0 & 4 \\
\hline 1999 & 1 & 0 & 0 & 0 & 1 \\
\hline 2000 & 6 & 1 & 0 & 1 & 8 \\
\hline 2001 & 8 & 0 & 0 & 0 & 8 \\
\hline 2002 & 2 & 1 & 0 & 0 & 3 \\
\hline 2003 & 6 & 0 & 1 & 0 & 7 \\
\hline 2004 & 3 & 3 & 0 & 0 & 6 \\
\hline 2005 & 7 & 1 & 0 & 0 & 8 \\
\hline 2006 & 5 & 1 & 0 & 0 & 6 \\
\hline
\end{tabular}


TABLE 16

Average number of days per year with different levels of rainfall for four nine-year blocks from 1971-2006 on Macquarie Island

\begin{tabular}{lcccc}
\hline $\begin{array}{l}\text { 9-year } \\
\text { intervals }\end{array}$ & R rainfall days & $\begin{array}{c}0.2-5.9 \\
\text { mm days }\end{array}$ & $\begin{array}{c}6-11.9 \\
\text { mm days }\end{array}$ & $\begin{array}{r}>12 \\
\text { mm days }\end{array}$ \\
\cline { 2 - 5 } $1971-1979$ & 62.4 & 261.3 & 32.3 & 8.9 \\
$1980-1988$ & 61.8 & 257.9 & 37.1 & 10.3 \\
$1989-1997$ & 44.0 & 272.1 & 38.9 & 11.7 \\
$1998-2006$ & 39.7 & 270.8 & 41.1 & 13.4 \\
\hline
\end{tabular}

(fig. 6). While the average number of days per month of zero rainfall is higher when there is greater potential benefit of this to rabbit breeding success (summer), only occasionally (fig. 9) are there enough days of zero rainfall to have any influence. Such benefit would, even so, be dependent on the pattern of heavy, burrow-flooding rainfall in relation to such dry periods.

\section{Impacts of wind direction, wind speed, temperature and rainfall trends on burrow-nesting petrels}

Changes to weather factors such as prolonged high or low temperature, wind direction and speed, in association with altered rainfall pattern, are believed to been responsible for the following:

- by 1999 , rat and mouse abundance had increased dramatically on Macquarie Island, based on the frequency of sightings;

- by 1999, rats unexpectedly disappeared from one traditionally heavily rat-impacted offshore stack petrel colony;

- by 1999 , rat distribution and abundance expanded with an apparent increase in availability of food such as $P$. hookeri seeds;

- an apparent change in conditions in shoreline beach strata leading to mice thriving on a proliferation of kelp fly (Coelopa curvipes Hutton, 1902 and C. nigrifrons Lamb, 1909) larvae which mice were seen eating in 1999; and

- by 1999 , there was a near-total dieback of $C$. plumosa, which provides protective vegetative cover against petrel burrow habitat deterioration and petrel predation, as well as an alternative food alleviating rat predation on petrels at offshore stack colonies.

Prior to 1996, Adamson et al. (1988) determined that northerly winds were becoming more prevalent at Macquarie Island, and there is sufficient evidence to indicate that this trend is continuing. The number of occasions in each 24-hour period for which the three-hourly wind direction between $0^{\circ}$ and $45^{\circ}$ was recorded indicates an increase not only in frequency (fig. 7) but also in duration (table 17). However, this same trend is not apparent at any level of daily persistence or annual frequency, if the wind direction is between $315^{\circ}$ and $45^{\circ}$ (fig. 8 ).

\section{DISCUSSION}

\section{Burrow-nesting petrels and vertebrate pests}

The vertebrate pest species established on Macquarie Island have had and continue to have a wide range of impacts on burrow-nesting petrel species. Feral Cats and Black Rats prey directly on eggs, young or adult birds, as did Weka, whilst European Rabbits denude vegetation and alter burrow conditions and availability. In doing so, they can expose burrows more to predation by skuas.

The consequences to burrow-nesting petrels of fluctuations in feral pest populations, changing interactions between species, and complex environmental changes were examined in this study. Observations of the responses of burrownesting petrels varied with the efforts and sequence of feral pest control, and were defined by the timing intervals of the monitoring study. During the period considered in this paper, Weka and cats were eliminated and there was a period of decreased rabbit population in response to the Myxoma virus.

Monitoring sites selected were ones occupied in reasonable abundance; therefore if predator activity was centred on areas with less abundant populations but with higher nesting densities, whole island population estimates extrapolated from transect data may have been affected. This may have been the case for Antarctic Prions and White-headed Petrels that had higher proportions of their populations at more widespread sites and at lower burrow densities than those at the monitoring sites. The overall response of petrels to most pest species is best represented by the population trends of Sooty Shearwaters (despite their discreet burrow concentrations), because of their wide distribution around the entire island. All other petrel species have not yet increased appreciably above population estimates indicated by Brothers (1984) and Brothers \& Ledingham (2008) despite having expanding nesting ranges.

With fewer rabbits present, Antarctic Prions have encountered decreased skua predation. With cats absent, Antarctic Prions should now become more abundant, despite the continued presence of rodents on Macquarie Island.

Sooty Shearwaters which breed in small, widely-distributed colonies in tussock, are more vulnerable to pest species than prions, especially to the impact of rabbits, and were extremely vulnerable to predation by cats. The entire population remained at risk to Weka until at least 1989. Removal of these pest species leaves Sooty Shearwaters accessible to an increasing abundance of rats. Sooty Shearwater 


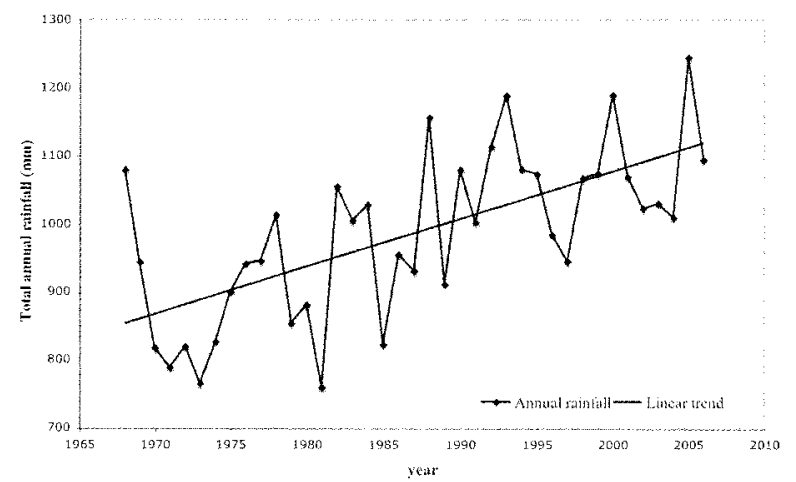

FIG. 2 - Trend in total annual rainfall from 1968-2006 from Meteorological Station data on Macquarie Island. (Linear trend line significantly different from zero $p<0.001$ )

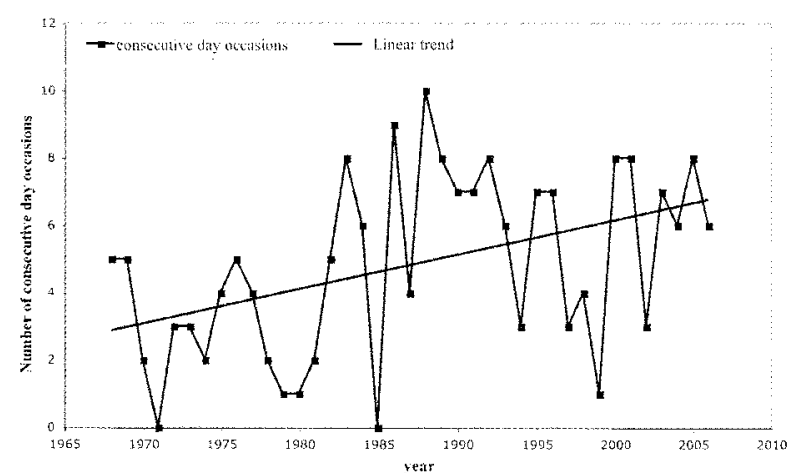

FIG.3-Between 1968 and 2006 , the trend in the frequency of consecutive 24-hour periods during which sufficient precipitation occurred to cause burrow flooding on Macquarie Island. (Linear trend line significantly different from zero $p=0.006$ )

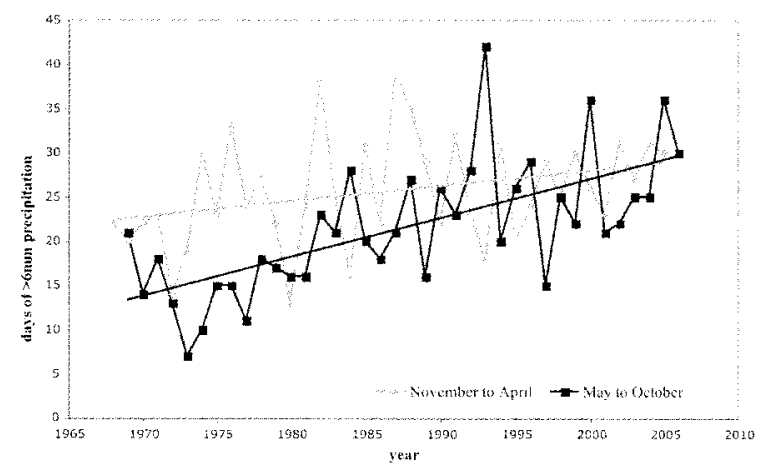

FIG. 4 - The annual amount of heavy rain (>6 $\mathrm{mm}$ per 24 hrs) at Macquarie Island 1968-2006 divided into greatest (summer: November 4-April) and least (winter: May-October) potential impact on breeding performance of burrow nesting petrels. (Linear trend lines show strong evidence that the rate of increase in the winter season is significant different from zero $p=0.006$ and is greater than in summer $p=0.05$.

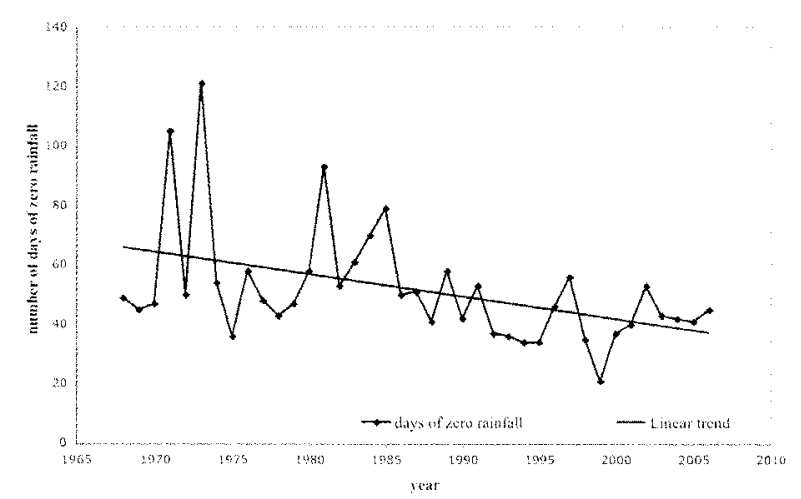

FIG. 5 - The number of zero rainfall days on Macquarie Island from 1968 to 2006. (Linear trend line is significantly different from zero $p=0.005$ )

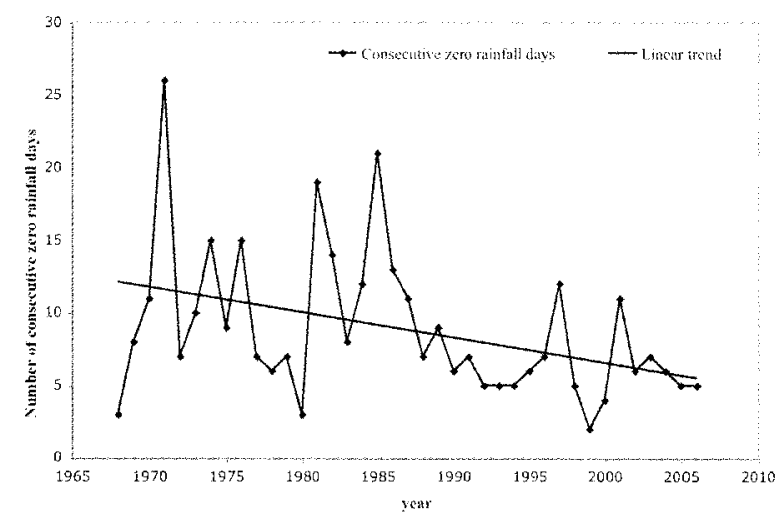

FIG. 6 - The frequency $>2$ consecutive days of zero rainfall between on Macquarie Island 1968 and 2006. Linear trend line is significantly different from zero $p=0.01$

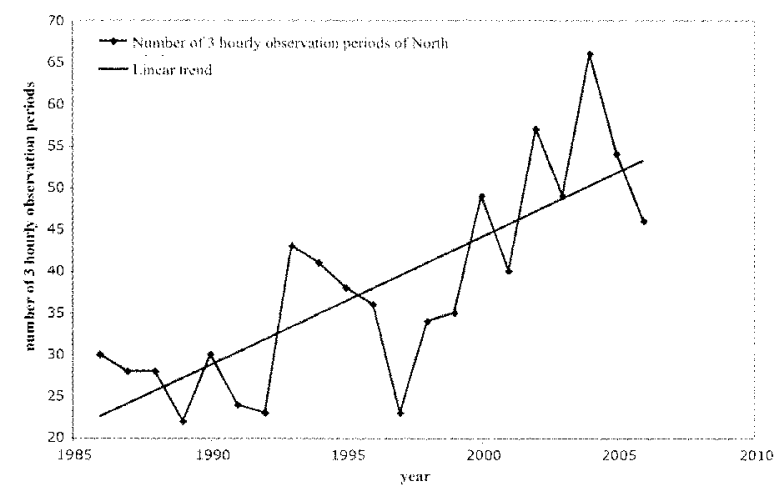

FIG. 7 - Trend in duration of wind from $0-45^{\circ}$ daily from 1986 to 2006 on Macquarie Island, based on three-hourly observations. (Linear trend line is significantly different from zero $p<0.001$ ) 


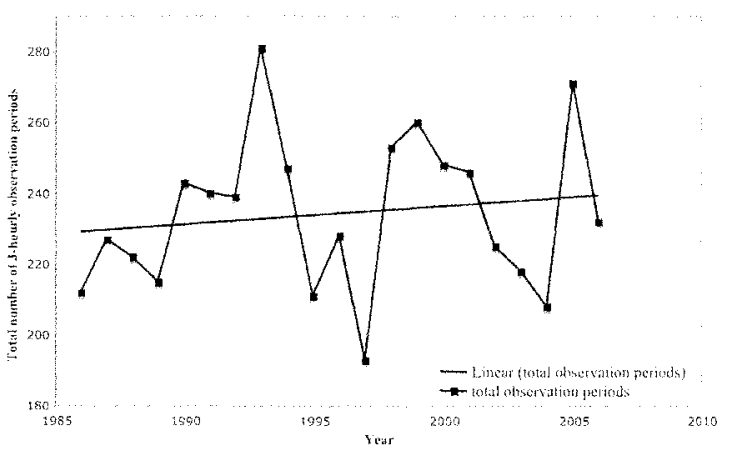

FIG. 8 - Total number of three-hourly observation periods annually in which wind direction between 315 and 45 degrees was recorded at Macquarie Island between 1986 and 2006. (Linear trend line observed slope greater than zero but not significantly different from zero $p=0.5$ )

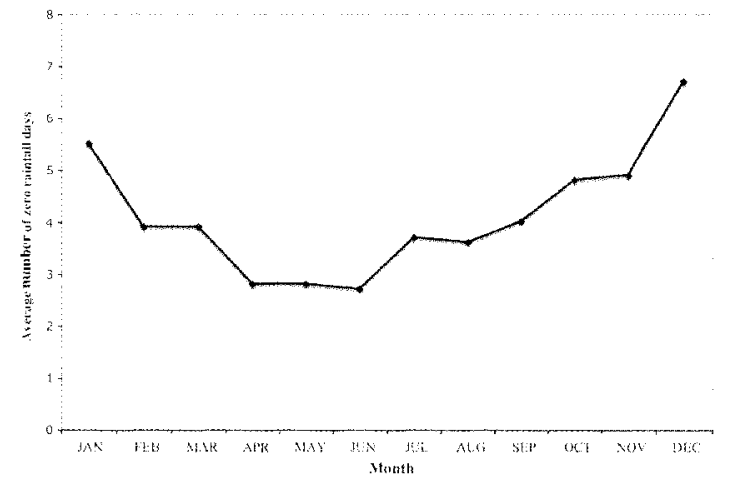

FIG. 9 - The average number of zero rainfall days in each month on Macquarie Island between 1968 and 2006.

TABLE 17

Duration of wind from 0-45 direction each day from 1986-2006 on Macquarie Island based on three-hour observations

\begin{tabular}{llllllllll}
\hline Year & \multicolumn{7}{c}{ Number of 3-hour records per day of $0-45^{\circ}$ wind direction } & Total \\
\cline { 2 - 5 } & 1 & 2 & 3 & 4 & 5 & 6 & 7 & 8 & \\
\hline 1986 & 22 & 9 & 1 & 0 & 0 & 0 & 0 & 0 & 32 \\
1987 & 25 & 4 & 3 & 0 & 0 & 0 & 0 & 0 & 32 \\
1988 & 23 & 5 & 0 & 0 & 0 & 0 & 0 & 0 & 28 \\
1989 & 16 & 6 & 0 & 0 & 0 & 0 & 0 & 0 & 22 \\
1990 & 28 & 2 & 0 & 0 & 0 & 0 & 0 & 0 & 30 \\
1991 & 20 & 3 & 1 & 0 & 0 & 0 & 0 & 0 & 24 \\
1992 & 16 & 4 & 1 & 2 & 0 & 0 & 0 & 0 & 23 \\
1993 & 30 & 11 & 1 & 1 & 0 & 0 & 0 & 0 & 43 \\
1994 & 31 & 7 & 2 & 1 & 0 & 0 & 0 & 0 & 41 \\
1995 & 22 & 4 & 6 & 1 & 2 & 0 & 0 & 0 & 35 \\
1996 & 27 & 4 & 4 & 1 & 0 & 0 & 0 & 0 & 36 \\
1997 & 12 & 7 & 2 & 1 & 1 & 0 & 0 & 0 & 23 \\
1998 & 19 & 11 & 3 & 1 & 0 & 0 & 0 & 0 & 34 \\
1999 & 21 & 7 & 5 & 2 & 0 & 0 & 0 & 0 & 35 \\
2000 & 22 & 15 & 4 & 4 & 3 & 1 & 0 & 0 & 49 \\
2001 & 22 & 12 & 12 & 5 & 0 & 0 & 1 & 0 & 52 \\
2002 & 21 & 14 & 9 & 6 & 2 & 2 & 2 & 1 & 57 \\
2003 & 22 & 10 & 8 & 2 & 5 & 2 & 0 & 0 & 49 \\
2004 & 29 & 7 & 14 & 8 & 4 & 3 & 1 & 0 & 66 \\
2005 & 32 & 9 & 8 & 3 & 1 & 1 & 0 & 0 & 54 \\
2006 & 25 & 14 & 5 & 1 & 1 & 0 & 0 & 0 & 46 \\
\hline
\end{tabular}


population trends clearly show the relationship between rabbit population control and a reverse in the shearwater population decline.

For the proportion of White-headed Petrel colonies still within tussock, destruction by rabbits has been highly erratic over time and patchy in extent. This habitat degradation has exposed this species to skua predation and the likelihood of burrow collapse and more regular flooding.

White-headed Petrels spend considerable time in aerial courtship whereas Sooty Shearwaters are reliant on surface courtship activity for which concealment by vegetation would be advantageous. For this reason Sooty Shearwaters are less resilient to the impact of rabbit destruction of colony habitat. There are few instances of shearwaters breeding where there used to be russock whereas White-headed Petrels persisted and have done so long after the tussock has been removed from around burrows.

During the period of low rabbit abundance prior to 1996 when eradication effort intensified (Copson 2004), cats probably reduced White-headed Petrel numbers significantly and were largely responsible for population decline throughout the monitoring period. Threatened Species Section (2007) mentioned a small increase in this species' abundance through the monitoring period, but this was erroneous, being based on a tentative estimate (Brothers 2000). Recent escalation in rabbit damage in areas previously little affected (A.Terauds pers. comm.) could foreshadow a significant decline in White-headed Petrel numbers. Hill 291 has been bare of tussock for at least 25 years and, despite this, White-headed Petrels have continued to occupy the site with census data to 1999 indicating a small decline in numbers. Other monitoring sites for this species have been subjected to significant habitat modification by rabbits since the mid-1970s with the majority of vegetation cover that offered protection from predators now absent. However, because rats are reliant on being within, or in close proximity to, adequate vegetative cover, and cats and Weka are now gone from the island, there is an overall decrease in predator pressure. Predation by skuas advantaged by exposed burrows and surface activity of petrels may increase, but there is also the possibility that skuas may be less successful when tackling White-headed Petrels in such open ground. White-headed Petrels are large and powerful birds that can take flight more easily from open ground than from within tussock.

Because rabbits and White-headed Petrels (or other petrel species of similar size), require burrows of similar diameter, there is likely to be a direct relationship between high rabbit abundance and a decline in the population of this petrel, due to competition. In contrast, smaller species, such as the Antarctic Prion, benefit from utilising existing rabbit burrows, constructing separate nesting burrows off them. This would minimise their high vulnerability to predators through surface activity such as burrow excavation.

Brothers \& Copson (1988) anticipated that, with the eradication of cats and Weka, burrow-nesting petrel populations would withstand rat predation in the long term. This hypothesis has yet to be verified. Grey-backed Storm-Petrels, Garrodia nereis (Gould, 1841), with their small size and a preferred nesting habitat that is occupied by rats, together with almost year-round presence ashore (Marchant \& Higgins 1990), are considered unlikely to regain former abundance if rats are not eliminated. Currently, this species is only suspected, not yet confirmed, to breed on the island. Rounsevell \& Brothers (1984) assigned a nominal figure of breeding population size to this species based on circumstantial evidence. No further evidence of this species was encountered between 1984 and 2000.

For all other species, rats are unlikely to prevent population increase, although they may hinder total population recovery. Despite rats being still present, with cats and Weka gone, a number of species have attempted to re-establish. Such activity did not occur when cats were prevalent. Environmental factors may change the distribution and abundance of rats in the future, which may increase the threat that they pose. Rats have been observed exploiting luxuriant $P$. hookeri growth for protective cover and food (from seeds) to extend their usual distribution limit. This may be a result of more favourable climatic conditions and decreased rabbit grazing. Any such increase in food availability could allow rats to become even more prolific and an increase in their distribution would further threaten certain petrel species. The single occasion of extreme cold in 1995, suggested as responsible for the disappearance of rats, and resulting in successful Blue Petrel breeding activity in the Langdon Point offshore stack colony, does not alone explain how petrels have persisted for so long there. Examination of meteorological records suggests that the persistent cold of July 1995 has been at least equalled twice, in July 1954 and in August 1964. This low frequency of extreme cold events could be sufficient to remove rats from offshore stacks and maintain these small petrel populations. However, this is dependent on the length of time interval before the rats reinvade. This time interval has not been determined but rats were absent from the offshore stack at least five breeding seasons subsequent to the 1995 event.

Contrary to Threatened Species Section (2007), now that potential alien predators (other than Black Rat) have been eliminated, diving-petrels could establish on the island, because historically their distribution included higher altitude habitat (Campbell 1901) well outside the current and future likely range of Black Rats. Given the likely favourable response of all petrel species to future (and past) vertebrate pest eradication, the population status of petrels will require regular evaluation if these responses are to be known and reported with any reasonable degree of accuracy (Baker et al. 2002).

\section{Cats and rabbits}

Cat eradication was not achieved until 1999, despite a sustained effort for over a decade (Copson 2004). In contrast to the gradual benefits from rabbits being kept in low numbers between 1984 and 2000 or from the eradication of Weka in 1989 (Copson 2004), a number of species showed immediate benefit from the rapid reduction, then eradication, of cats. Although this infers that cats were the most destructive of these pests, it was cats in combination with rabbits and Weka that were responsible for the demise of so many of the islands indigenous species. The extent to which each pest species and their combined effects contributed to the demise of indigenous species probably varied considerably over time because of the large population fluctuations of introduced species, regardless of human intervention.

Until at least 2003, rabbit numbers had effectively been maintained at around $10-15 \%$ of the pre-myxomatosis level of around 150000 (Copson 2004). This was considered important to improve the likelihood of cats being eradicated because while rabbit numbers were contained long enough for cats to be eradicated, failure to maintain this control 
has seen rabbit numbers and damage to vegetation escalate (Bryant \& Shaw 2007). Ongoing control was compromised by the failure to ensure supplies of Myxoma virus to maintain an effective inoculation program. Any perception that cat eradication was somehow a catalyst for the rabbit population increase that subsequently occurred is erroneous and most convincingly disputed by the historical trends in rabbit abundance on the island irrespective of cat numbers through that time (Copson et al. 1981, Copson 2004). Cat predation on rabbits has never been sufficient to regulate rabbit numbers, which is not surprising considering that there were only ever known to be approximately 250 adult cats on the island (Brothers et al. 1985).

Feral pest management processes identified the need for cats and Weka to be eliminated so that burrow-nesting petrels could recolonise (Parks and Wildlife Service 2006). This was achieved, averting even greater impacts on remaining petrel populations. Cats themselves were believed to have been largely responsible for Weka extermination because such a rapid disappearance could not be accounted for by hunting alone (Copson 1995). Weka impact on petrels was reduced when increased rabbit grazing limited the safe foraging range of Weka. Based on the results of petrel monitoring, the prediction that petrels would face increased predation from cats as a consequence of rabbit control (Brothers 1984), seems to have occurred prior to cats being completely eradicated.

The permanent rabbit count areas (Copson et al. 1981) failed to accurately reflect the extent of recent rabbit increases because counting rabbits in habitat where they are less conspicuous (such as on steep tussock-covered slopes) is inaccurate. In addition, vegetation recovery resulting from reduced rabbit grazing pressure altered rabbit visibility in many count areas from 1988 to 1999 , thus compromising comparisons with past counts. With cats and Weka gone, it will be important to monitor the impact of rabbits, especially at White-headed Petrel monitoring sites, which were at varying stages of measurable rabbit impact.

The relationship between rabbit and skua distribution and abundance, which in turn affects the extent of skua predation on petrels, remains complex. Rabbit control, and the concurrent contraction of skua breeding range to become more aligned with the proximity of indigenous food sources, is likely to have considerably reduced skua pressure on petrels. However, the extent of this association is unclear. While rabbit distribution and abundance prior to myxomatosis may have supported more skuas in total with nesting territories more widely distributed, it is not clear if these skuas were consuming more or fewer of the petrels nesting there. Skuas may have consumed more petrels because availability of rabbits had induced skuas to spend more time in petrel-nesting areas than usual. However, if these areas were not claimed as nesting territories by skuas, and so being held against visiting skuas, many more skuas may have been able to visit and utilise the petrel colonies as a food source.

\section{Recolonisations}

Since the first known observation of Cape Petrels occupying Macquarie Island slopes in October 1999, there was similar activity in the subsequent two years until breeding was confirmed in 2002 (Threatened Species Section 2007). However, it is not known whether breeding occurred prior to this without being detected, particularly if breeding failed soon after egg laying. While Threatened Species Section (2007) speculates that because Cape Petrels are conspicuous they would not have been overlooked as a breeding species, Law \& Burstall (1956) suspected nesting by this species in 1951 on Anchor Rock, which is relatively close to the current breeding site. Furthermore, in 1976 Lugg et al. (1978) suspected nesting of Cape Petrels on Anchor Rock and since then there have been frequent observations of birds alighting there. Observations of Cape Petrels on nearby Gorilla Rock have also been made. Therefore, this seems unlikely to be a case of new colonisation; more probably management actions on the island have created sufficiently safe conditions for the small numbers that have always been nesting offshore to now move to more suitable nesting sites. However, Threatened Species Section (2007) notes it as being a conspicuous and readily identifiable species, with no mention made by Hamilton (1894) or Falla (1937) of it being resident. Other surface-nesting species, the Antarctic Tern and the Kelp Gull, have been affected significantly by the presence of introduced predators to Macquarie Island with most nesting having been confined to offshore land masses with some degree of protection from predators and inundation by seas. All these species have apparently responded to the absence of cats and Weka by attempting to breed in sites where these predators would previously have had access, yet the ongoing presence of rats has not deterred them.

In addition to the impacts of introduced vertebrates on indigenous fauna on Macquarie Island, at least two species, the Macquarie Island Rail, Rallus philippensis macquariensis (Hutton, 1879), and the Macquarie Island Parakeet, Cyanoramphus novaezelandiae erythrotis (Salvadori, 1891), have become extinct (Taylor 1979). It remains to be seen whether similar species that occur on the closest landmasses become established when the opportunity arises, once the cause of their extinction on Macquarie Island, has been addressed. The Red-crowned Parakeet, $C$. novaezelandiae (Sparrman, 1787), and the Buff-banded Rail, Rallus philippensis (Gray, 1843), from New Zealand populations are likely candidates. However, during 25 years of vagrant bird species observations, no records of parakeets and only one rail record, that of a Baillon's Crake, Porzana pusilla (Pallas, 1776), have been made (Copson \& Brothers 2008). It is unknown whether the Macquarie Island Rail occupied a similar ecological niche to the Weka but they probably would have had some feeding habits in common, including predation of petrels. In the absence of both species, it is possible that certain species, such as the orchid, Nematoceras dienemum (D.L.Jones)D.L.Jones, M.A.Clem et Molloy, bulbs of which were sought after by Weka, will increase in distribution or abundance, just as would $N$. sulcatum M.A.Clem et D.L.Jones. It is also possible that species such as the Common Blackbird, Turdus merula Linnaeus, 1758 , and Song Thrush, Turdus philomelos C.L. Brehm, 1831, which have been infrequent vagrants on Macquarie Island, will establish and their impacts may warrant management consideration. The Common Starling, Sturnus vulgaris Linnaeus, 1758, is well established. However, unlike the Common Blackbird and Song Thrush, Common Starlings have managed this, despite predators, probably because their breeding sites are often on inaccessible cliff crevices and because they largely feed in open areas. Both the Song Thrush and the Common Blackbird confine themselves within or adjacent to tall tussock grassland where, at least in the past, their existence has been short-lived probably due to predators. Surprisingly, the Redpoll Carduelis 
flammea (Linnacus, 1758), managed to establish despite being vulnerable to indigenous predators (gulls and skuas) and to all vertebrate pests. Undoubtedly, species with a flocking habit such as starlings and Redpolls will colonise new places more readily by arriving in numbers. Therefore, it is considered that the Red-crowned Parakeet would precede other colonising species.

To date, management response to discovery of alien plant species, thought to be recent arrivals to the island, has been to exterminate them (Copson \& Whinam 2001) and Brothers \& Davis (2008) discuss the issue in relation to alien marine life encountered. This needs to be further considered in relation to the avian arrivals that will establish in the absence of, in particular, Weka and cats. The likelihood of new bird species establishing on the island may have increased due to climate change, as there have been changes in wind directions more favourable for southward movement (Adamson et al. 1988). This wind direction trend is continuing (fig. 7 , table 17).

\section{Ongoing problems with rats}

Copson (2004) outlined a localised rat eradication and control program, initiated as part of the petrel monitoring work in November 1999 to coincide with eradication of Weka and cats. At this time, there was increased petrel burrowing activity coupled with, possibly, drier conditions less favourable for maintaining C. plumosa vegetative cover and soils resistant to skua excavation. This resulted in poor petrel-breeding performance and, therefore, impeded recolonising of Macquarie Island. With an immediate objective of rat eradication from all offshore stacks, ongoing control on the shore adjacent to stacks was instigated using a series of rat poison bait stations in an effort to both prevent reinvasion and to create rat-free nesting habitat to which petrel populations could expand. This would also help create a situation where predation by rats would be less devastating to petrel populations and so allow petrel populations to increase. Coincidentally, examples of the viability of such a strategy had been illustrated by the fact that petrels had already recolonised Macquarie Island via the only rat-free offshore stack. Data from the Langdon Point colony indicate that keeping stacks rat-free to improve petrel-breeding performance is viable. Jouventin et al. (2003) also provide evidence of the benefit to petrel-breeding performance through maintaining population control of rats. However, the perceived risk of poison immunity developing in the rat population prior to implementation of the rat eradication plan was the reason that localised rat control for petrel colonies ceased in 2003 (Copson 2004). Maintaining this effort specifically on offshore stacks should have posed minimal risk of poison immunity, but there was also uncertainty as to whether appropriate effort could be directed at keeping the offshore stacks in a rat-free state. Reoccupation of Macquarie Island at Green Gorge by Blue Petrels is not only the most significant example of a small-sized petrel species returning from offshore stacks to breed but is also the first occasion of any breeding occurring at such a low altitude within the distribution of rats. This reinforces the interpretation that rats were never as significant in the demise of petrels as Weka, cats and rabbits. The dominant vegetation on offshore stacks, C. plumosa, which flourishes with the intensive soil disturbance of petrel burrowing activity, regresses naturally seasonally. However, the petrel-affected, well-drained soils and the effect of rat-browsing are likely to shorten the period of protective burrow cover there. Burrow collapses together with increased skua predation are inevitable consequences of this reduced cover.

Any petrel population increase resulting from rat eradication will lead to greater pressure from burrowing activity exacerbating loss of vegetative cover, deterioration in the burrowing habitat and eventual population decline on offshore stacks. The safest way to prevent this would be to have rat-free habitat onshore adjacent to the stacks created at the same time, although the recolonising already adjacent to the Green Gorge stack indicates that rats are not entirely preventing this without such management intervention. However, in the immediate future at least, rabbit grazing impacts that dictate to a large extent the distribution of rats, will assist, not impede, the rate that the smaller petrels can recolonise Macquarie Island in the absence of Weka and cats.

In recent times, and certainly by 1999 , rats had been observed in much greater overall abundance on Macquarie Island (Copson, Brothers unpubl. data). Since then rats have not been prevented from occupying stacks, so it would be a wise strategy to maintain offshore stacks free of rats in the event that an island-wide eradication attempt is unsuccessful or does not eventuate for any reason.

Copson (2004) discussed the possible causes for the observed large increase in rodent (rats and mice) abundance, with global warming implicated. The long-term effects of changed utilisation by rats of $P$. hookeri (Shaw et al. 2005), and perhaps of other plant species as well, is complex. This is especially so with climate change adding uncertainty to subtle yet potentially significant ecological relationships on Macquarie Island, and is even more complicated if an eradication attempt (Copson 2004) leaves the island without rabbits but still with rodents. Increased rates of reproductive development in at least certain plant species together with the ameliorating climatic conditions forecast for the island (Tweedie 2000) may have already been responsible, at least partially, for increasing rodent abundance. Presumably these factors may also assist plant recovery from rabbit impacts as implied by Tweedie (2000), but the causes of such relationships are likely to remain unclear, particularly if eradication of rabbits occurs. At present, the rat's ability to have such a big impact depends on the extent of vegetation cover, which increased because rabbit numbers had been maintained at a greatly reduced level. Although such recovery of vegetation may increase rat populations and broaden their distribution to further overlap with sectors of the petrel population, an increasing abundance of alternative food for rats other than petrels (e.g., seeds) may reduce the impact of rats on petrels. Copson (2004) presented a strategy for achieving the eradication of rodents and rabbits and outlined the risks of an attempt to eradicate all species simultaneously. For the majority of burrow-nesting petrels, the eradication of rabbits but not rodents, would be a minimum acceptable target and is a sensible objective if an eradication attempt on all species cannot proceed or fails.

When the conservation status of burrow-nesting petrel species are threatened by other anthropogenic causes such as by some of the world's fisheries (Weimerskirch et al. 1999, de L. Brooke \& Croxall 1999, Brothers et al. 1999, Sullivan et al. 2006), the added impact of rats may become more significant. The smaller petrel species which face rat predation of eggs, chicks and also adults (Warham 1990) are fortunately not doubly disadvantaged by becoming fisheries bycatch as are some of the larger petrels. However, 
of the larger species now on the island, Sooty Shearwaters, Cape Petrels, particularly Grey Petrels, and the potentially recolonising species White-chinned Petrels, Procellaria aequinoctialis Linnaeus, 1758 , are all highly vulnerable because of increased mortalities in fisheries. Grey Petrels and White-chinned Petrels in particular are susceptible to being caught on hooks in longline fisheries. They are little deterred by bird-scaring lines, aimed at excluding their access to baited hooks (Brothers et al. 1999), in contrast to other susceptible seabird species. In addition they are also highly proficient pursuit divers, feed throughout both day- and night-time, are unafraid to forage persistently immediately alongside fishing vessels and take advantage of ship's lighting to pursue baited hooks. These traits impose considerable limitations upon the effectiveness of all mitigation measures currently employed to prevent longline fisheries mortalities which, combined with such low abundance of these species breeding on Macquarie Island, should dictate that they are not put at further risk by any such fishing activity occurring near the island. One immense benefit of vertebrate pest management to allow recovery of such petrel species on Macquarie Island will be the added assistance this gives to the conservation of such species in the face of high fisheries mortalities.

\section{Climate change impacts}

It is likely that, as species now adapted to one of the worlds' most equitable climates, indigenous residents of Macquarie Island will be particularly susceptible to even relatively small changes in the climatic conditions. This is becoming increasingly apparent for vertebrate species, through the impacts of climate change on habitat. The timing of this has complicated the accurate interpretation of management actions and their impact. For example, the dramatic increase in the abundance of rodents is coincidental with, but not necessarily a consequence of, cat eradication, because cats were insufficiently abundant (Jones 1977, Brothers et al. 1985) and had adequate alternative food supplies. If nothing else, this should reinforce the necessity for planned management of vertebrate pests to proceed, preferably sooner rather than later, in order to avert rapid progression of rabbit and rodent impacts on the island under climatic conditions more suited to these species. Indications of relationships discussed between specific climatic conditions and fluctuations in pest species abundance need to be taken into consideration with respect to the proposed eradication plan. The question of whether climatic conditions for greatly improving eradication prospects can be predicted from the island's long-term meteorological records needs to be answered. Such specific relevant climatic conditions have been identified here and those conditions more suited to the logistic requirements of an eradication. attempt (Copson, 2004) are also identifiable. Aside from the complications of a climate increasingly more suited to proliferation of the remaining vertebrate pests, there is the possibility that eradication of the three remaining vertebrate pests may be unachievable. The significance, therefore, of relationships such as that between precipitation patterns and water table movement must not be underestimated with respect to their impacts now and in the future on both introduced and indigenous species on the island. A more detailed study of this relationship is needed together with combined effects of other weather features that are also changing (Adamson et al. 1988, Jacka et al. 2004, Pendlebury \& Barnes-Keoghan 2007).
The perceived heavier rainfall, soil erosion and frequency of petrel burrow flooding events have been supported by evidence of increasing heavier rainfall. More frequent flooding of rabbit burrows has probably also occurred and would account for the recent tendency for the highest rabbit abundance and resulting habitat destruction to be the greatest in well-vegetated steep coastal localities (i.e., less flood-prone habitat). More frequent heavier rainfall (sufficient to cause rabbit burrow flooding) is likely to cause altered, topographically-related rabbit population increase, because rabbit kitten mortality due to wet burrows will be greatest throughout much of the traditionally occupied rabbit habitat. On well-vegetated steep slopes that are considered less susceptible to burrow flooding and which have protection from the impact of the combination of cold and moisture on kitten survival, the population increase in the absence of myxomatosis control inevitably led to the substantial increase in habitat destruction here. There is no convincing evidence to support alternative hypotheses such as increasing immunity of rabbits to myxomatosis or prolonged breeding in response to more favourable winter weather conditions (Parks and Wildlife Service unpublished records).

While Tweedie (2000) found mean monthly precipitation to be decreasing mainly between late autumn and early spring, no evidence has been presented to indicate greater breeding performance of rabbits outside their usual breeding timetable (Skira 1978, 1980). Of further relevance may be an evaluation of the 24-hour rainfall pattern in the 0.2 $\mathrm{mm}-5.9 \mathrm{~mm}$ range. With an average of 266 days per year (1968-2006 meteorological data) upon which such rainfall occurs, most ecological impact may be a consequence of a change occurring in the daily pattern only of this amount of precipitation. In relation to rabbit kitten survival alone, more constantly wet, but not necessarily flooded, burrows may be of greatest relevance. Even relatively small amounts of precipitation within shorter timeframes daily could affect kitten survival. However, a more precise understanding of the relationship between rainfall amounts and water table response would be required to investigate this. While this does support observations such as those of increases in burrow flooding events and erosion rates, other weatherrelated changes indicated are not so readily explained. In some months, for example, there can be as many as 17 days of no rainfall that may have short-term ecological impact. It was unexpected, however, to find that there was not a trend towards more consecutive zero rainfall days each year with the island thus experiencing greater extremes of dryness as well as wetness. Further, in relation to the observations of dry condition impacts, Whinam \& Copson (2006) discuss this concerning sphagnum moss, and Pendlebury \& Barnes-Keoghan (2007) propose that, despite evidence of actual weather conditions, evaporation as a consequence of higher wind speeds over the island may be responsible. Relative humidity is decreasing on the island which may counterbalance the increased net radiation and precipitation occurring, and recharge of soil moisture may be decreasing (Tweedie 2000). Such a process could account, therefore, for the visual evidence described of drier conditions irrespective of precipitation increase.

Previously there has been no attempt to look in detail at the nature of precipitation patterns at Macquarie Island with interpretation of meteorological records tending to focus on overall totals to give long-term trends. Tweedie (2000) suggested, however, that the overall increase in precipitation is in the form of more intense rainfall periods 
indicated by increases in both maximum daily precipitation and precipitation standard deviation. Williams (unpublished BOM data analysis 1968-2005) found that the rising trend in incidence of days with low mean sea level barometric pressure, (around $970 \mathrm{hpa}$ ), is the reason that rainfall is increasing, i.e., higher precipitation rate is strongly correlated with lower barometric pressure at the island. The reason for this occurrence is because the island's weather is being influenced by a high-index state of Southern Annular Mode, being in a region of increasing westerly winds potentially bringing more moisture (Pendlebury \& Barnes-Keoghan 2007). Wind strength and its relationship to persistence and direction were not assessed in their study and could be an important additional factor influencing the arrival prospects of terrestrial airborne species.

It is not known how petrels, for example Grey Petrels which were not found to be breeding on Macquarie Island until 1993, and other seabirds have the capacity to immediately exploit recolonising opportunities created by extermination of introduced predators. The return of Grey Petrels to Macquarie Island is believed to be due to individuals coming from elsewhere. This is supported by the very rapid population increase following the initial arrival (and discovery) of small numbers of breeding pairs on the island. Locally displaced species, such as Antarctic Terns, Kelp Gulls and perhaps Cape Petrels, only made an attempt to reoccupy new breeding sites when the opportunity, in the absence of predators, first arose.

In contrast to the population history outlined for the Grey Petrel, the Soft-plumaged Petrel is believed not to have experienced an entirely disrupted breeding association with the island in the period of cat and Weka habitation. Unlike the smaller petrel species, none of Macquarie Island's offshore stacks or islands that could have served as a refuge, contain nesting habitat suitable for these larger petrels. Reasons for the wide range of impacts caused by introduced pests on each petrel species have been discussed by Brothers (1984).

After the Grey Petrel, the White-chinned Petrels considered to have formerly been a breeding species on Macquarie Island, possibly would have been the first petrel species eliminated. The White-chinned Petrel would have been unable to persist even in low numbers because of its diurnal activity habits ashore and typically large, accessible burrows. Accounts of wild dogs as early as 1815 (Cumpston 1968) may be sufficient explanation for this species' disappearance even before it was documented as a breeding species. Whether this species, after such a long disassociation with the island, manages to re-establish will only be revealed in the future.

\section{Future studies}

Future censuses must accommodate the fact that all prionsized burrows may not belong to just one prion species, because other similar-sized species will begin to recolonise the main island. These may include, in potentially intermixed colonies, the Blue Petrel, Fulmar Prion, Fairy Prion, Common Diving-Petrel and South Georgian Diving-Petrel. Likewise, shearwater-sized burrows could become intermixed with the similar-sized burrows of several more species. This may mean increased difficulty in trying to ascertain which species is occupying each burrow. Drawbacks of trying to do this include the fact that it can be destructive to fragile nesting habitat, disruptive to disturbance-sensitive species, logistically impractical on a regular basis or over the same specific locality repetitively. Irrespective, this will still not account for the proportion of breeding pairs whose breeding attempt was unsuccessful or was deferred, a frequent occurrence (Waugh et al. 2003). Unsuccessful or deferred breeding attempts are at least two reasons why empty burrows are not necessarily occupied by breeding pairs, and why the assumption that each active burrow represents a breeding pair may not be a false assumption, as stated by Lawton et al. (2006). It is not known just how accurately population size can be determined, using the assumption that each active burrow represents one breeding pair. However, while even burrows that appear to be active may not actually be used for breeding in that particular year, indications of population trends should be possible from comparisons between years of active burrows counted. Measuring call playback response as a means of ascertaining burrow occupancy is efficient and benign but imprecise because not all birds that are present respond, some that do respond may not be breeding and pairs that leave the egg unattended for periods will be missed. But the results of studying specific breeding species' habits in detail to account for such variability can then be applied to broad population monitoring as a means of improving accuracy in burrow occupancy rates. Such studies, in themselves, can create disturbance-induced biases and also require considerable, long-term investment of resources so that potential high inter-annual variability can be accounted for. A major problem arises where different species occur in abundance at burrows that are indistinguishable, which is likely to become a rapidly increasing problem as species recover their former distribution and abundance on Macquarie Island. Application of techniques for determining burrow occupant identity, rates of burrow occupancy and evidence of breeding such as the infra-red camera "burrowscope" (Markwell 1997 , Hamilton 1998,2000) could assist to measure populations of petrels more accurately on Macquarie Island provided such equipment can cope efficiently with fragile burrowing habitat, a high incidence of long, interconnected, deep, muddy and often partially flooded burrows, and then differentiate species that have very similar physical characteristics.

The importance of relatively small but abundant burrownesting seabirds as major consumers of marine resources (Brooke 2004) is easily overlooked at Macquarie Island where their populations are presently small compared to the vast numbers of other species (e.g., penguins). This balance is anticipated to change dramatically with petrel population recovery after the fulfilment of the management objectives for vertebrate pests (Parks and Wildlife Service 2006). Therefore, the energetic requirements of future, not current, burrow-nesting petrel populations should be considered in relation to any management of marine food resources.

For all the uncertainty of the various ways in which seabirds may be affected ashore by a changing climate, factoring in such changes offshore adds substantially to the complexity of understanding causes of species population trends. For instance, the natural climatic variability and Macquarie Island's proximity to the Antarctic Polar Frontal Zone and to the Antarctic Circumpolar Current are likely to be significant influences on species, in particular, during the breeding season when foraging is restricted. Even slight variations in such influences could have major impacts. Vastly more information will be necessary to determine whether processes of climate change in marine and terrestrial environments are having greater effects than other known or more obvious influences on the abundance of species. 
Removing the impact of rabbits and rats from the equation would be of immense assistance in simplifying this complex puzzle.

\section{ACKNOWLEDGEMENTS}

We thank the Royal Society of Tasmania in association with Suzanne Skira for inviting the submission of this paper for inclusion in a commemorative publication to Dr Irynej Skira. This paper is an appropriate inclusion because the information it contains is from a place for which Irynej had fond memories in his role as the first Tasmanian Parks and Wildlife Service representative to undertake work on Macquarie Island. His studies there on rabbits, in particular, formed the basis of invaluable monitoring that has continued now for over 30 years. The current study was made possible by the support of the Australian Antarctic Division and the Tasmanian Parks and Wildlife Service, particularly its current Director Peter Mooney who facilitated the opportunity to collate the information gathered. Ashleigh Wilson of the Bureau of Meteorology, Coffs Harbour (formerly stationed at Macquarie Island), generously offered her time and help in accessing metcorological data. Assistance with using the data was also provided by Dave Williams, and we are grateful to the Australian Bureau of Meteorology for access to and use of these records. Kerrin Jeffrey was a great help in the preparation of the manuscript as were Tim Reid and Lisa Gurney for chasing reference material and Geoff Copson for useful discussion throughout the course of the study. Glen McPherson kindly assisted with weather data statistics. We thank Sheryl Hamilton and Margaret Davies for their efforts in the final production of this manuscript.

\section{REFERENCES}

Adamson, D.A., Whetton, P. \& Selkirk, P.M. 1988: An analysis of air temperature records for Macquarie Island: Decadal warming, Enso cooling and Southern Hemisphere circulation patterns. Papers and Proceedings of the Royal Society of Tasmania 122(1): 107-112.

Baker, G.B., Gales, R., Hamilton, S. \& Wilkinson, V. 2002: Albatrosses and petrels in Australia: a review of their conservation and management. Emu 102: 71-97.

Brooke, M. de L. 2004: The food consumption of the world's seabirds. Proceedings of the Royal Society London B (Suppl.) 271: S246-S248.

Brothers, N. 2000: Recovery of burrow-nesting seabirds on Macquarie Island in response to the Feral Cat Eradication Program. Unpublished internal report, Tasmanian Parks and Wildlife Service, Hobart: $4 \mathrm{pp}$.

Brothers, N. \& Davis, G. 2008 Two new records of marine mussels (Mytilidae) from subantarctic Macquarie Island. Molluscan Research 28(2): 142-144.

Brothers, N. \& Ledingham, R. (2008) The avifauna of Bishop and Clerk islets and its relationship to nearby Macquarie Island. Papers and Proceedings of the Royal Society of Tasmania 142(1): 117-122

Brothers, N.P. 1984: Breeding distribution and status of burrownesting petrels at Macquarie Island. Australian Wildlife Research 11: 113-131.

Brothers, N.P. 1985: Breeding biology, diet and morphometrics of the Macquarie Shag, Phalocrocorax albiventer purpurascens, at Macquarie Island. Australian Wildlife Research 12: $81-94$.

Brothers, N.P., Cooper, J. \& Lokkeborg, S. 1999: The Incidental Catch of Seabirds by longline fisheries Worldwide Review and Technical Guidelines for Mitigation. FAO Fisheries
Circulars No 937. Food and Agriculture Organization of the United Nations, Rome: 99 pp.

Brothers, N.P. \& Copson, G.R. 1988: Macquarie Island flora and fauna management-Interpreting progress and predictions for the future. Papers and Proceedings of the Royal Society of Tasmania 122(1): 129-136.

Brothers, N.P., Eberhard, I.E., Copson, G.R. \& Skira, I.J. 1982: Control of rabbits, Oryctolagus cuniculus, on Macquarie Island by myxomatosis. Australian Wildlife Research 9(3): $477-485$.

Brothers, N.P. \& Skira, I.J. 1984: The weka on Macquarie Island. Notornis 31: 145-154.

Brothers, N.P., Skira, I.J. \& Copson, G.R. 1985: Biology of the feral cat, Felis catus (L) on Macquarie Island. Australian Wildlife Research 12: 425-436.

Bryant, S. \& Shaw, J. 2007: Threatened Species assessment on Macquarie Island. Internal Report, Department of Primary Industry Water and Environment. Hobart: $21 \mathrm{pp}$.

Campbell, A.J. 1901: Nests and Eggs of Australian Birds. The author, Sheffield, Tasmania: $1100 \mathrm{pp}$.

Chown, S.L. \& Smith, V.R. 1993: Climate change and the shortterm impact of feral house mice at the sub-Antarctic Prince Edward islands. Oecologia 96: 508-516.

Copson, G.R. 1995: An integrated Vertebrate Pest Strategy for subantarctic Macquarie Island. Proceedings of the 10th Vertebrate Pest Control Conference, Hobart, May 1995: 29-33.

Copson, G.R. 2002: Integrated Vertebrate Pest Management on Subantartic Macquarie Island 1997-2002. Final Report for National Heritage Trust, Department of Primary Industries Water and Environment, Hobart: 31 pp.

Copson, G.R. 2004: Draft Plan for the Eradication of Rabbits and Rodents on Subantarctic Macquarie Island. Report for National Heritage Trust, Department of Primary Industries Water and Environment, Hobart: 76 pp.

Copson, G.R. \& Brothers, N.P. 2008: Notes on rare, vagrant and exotic avifauna at Macquarie Island, 1901-2000. Papers and Proceedings of the Royal Society of Tasmania 142(1): 105-116.

Copson, G.R., Brothers, N.P. \& Skira, I.J. 1981: Distribution and abundance of the rabbit, Oryctolagus cuniculus (L.), at subantarctic Macquarie Island. Australian Wildlife Research 8: 597-611.

Copson, G.R. \& Whinam, J. 1998: Response of vegetation on subantarctic Macquarie Island to reduced rabbit grazing. Australian Journal of Botany 46(1): 15-24.

Copson, G.R. \& Whinam, J. 2001: Review of ecological restoration program at subantarctic Macquarie Island: Pest Management progress and future directions. Ecological Management and Restoration 2(2): 129-138.

Cumpston, J.S. 1968: Macquarie Island, ANARE Scientific Reports, Series A(1), Australian Antarctic Division: 380 pp.

De L. Brook, M. \& Croxall, J. 1999: Saving seabirds into the new millennium. World Birdwatch 21 (1): 2-11.

Dixon, G. 2001: Management strategy for walking tracks and access corridors in Macquarie Island Nature Reserve, Unpublished report. Parks and Wildlife Service, Tasmania: $36 \mathrm{pp}$.

Falla, R.A. 1937: Birds. British, Australian and New Zealand Antarctic Research Expedition (BANZARE) Reports, Series B, Vol. 2: 288 pp.

Hamilton, A. 1894: Notes on a visit to Macquarie Island. Transactions of the New Zealand Institute 27: 559-79.

Hamilton, S. 1998: Determining burrow occupancy, fledging success and land-based threats to mainland and near-shore island sooty shearwater (Puffinus griseus) colonies. New Zealand Journal of Zoology 25: 443-453.

Hamilton, S.A. 2000: How precise and accurate are data obtained using an infra-red scope on burrow-nesting Sooty Shearwaters, Puffinus griseus? Marine Ornithology 28(1): 1-6. 
Jacka, T.H., Budd, W.F. \& Holder, A. 2004: A further assessment of surface temperature changes at stations in the Antarctic and Southern Ocean, 1949-2002. Annals of Glaciology 39: 331-338.

Jones, E. 1977: Ecology of the feral cat Felis catus (L.), (Carnivora Felidae) on Macquarie Island. Australian Wildlife Research 4(4): 249-262.

Jones, E. \& Skira, I.J. 1979: Breeding distribution of the great skua at Macquarie Island in relation to numbers of rabbits. The Emu 79: 19-23.

Jouventin, P., Bried, J. \& Micol, T. 2003: Insular bird populations can be saved from rats: a long-term experimental study of white-chinned petrels Procellaria aequinoctialis on Ile de la Possession (Crozet archipelago). Polar Biology 26 371-378.

Law, P.G. \& Burstall, T. 1956: Macquarie Island. ANARE Interim Rep. No. 14. Melbourne: Antarctic Division, Department of External Affairs: 48 pp.

Lawton, K., Robertson, G., Kirkwood, R., Valencia, J., Schlatter, R. \& Smith, D. 2006: An estimate of population sizes of burrowing seabirds at the Diego Ramirez archipelago, Chile, using distance sampling and burrow-scoping. Polar Biology 29: 229-238.

Lugg, D.J., Johnstone, G.W. \& Griffin, B.J. 1978: the outlying islands of Macquarie Island. The Geographical Journal 144(2): 277-287.

Marchant, S. \& Higgins, P.J. (eds) 1990: Handbook of Australian, New Zealand and Antarctic birds. Volume 1, Ratites to ducks. Oxford University Press, Melbourne: 1440 pp.

Markwell, T.J. 1997: Video camera count of burrow-dwelling fairy prions, sooty shearwaters, and tuatara on Takapourewa (Stephens Island), New Zealand. New Zealand Journal of Zoology 24: 231-237.

Parks and Wildlife Service 2006: Macquarie Island Nature Reserve and World Heritage Area Management Plan, Parks and Wildlife Service, Department of Tourism, Arts and the Environment, Hobart: $176 \mathrm{pp}$.

Pendlebury, S.F. \& Barnes-Keoghan, I.P. 2007: Climate and climate change in the sub-Antarctic. Papers and Proceedings of the Royal Society of Tasmania 141(1): 67-82.

Rounsevell, D.E. \& Brothers, N.P. 1984: The status and conservation of seabirds at Macquarie Island. In Croxall, J.P., Evans, P.G.H. \& Schreiber, R.W. (eds): Status and Conservation of the World's Seabirds. ICBP, Cambridge: 587-592.

Scott, J.J. 1988: Rabbit distribution history and related land disturbance on Macquarie Island. Papers and Proceedings of the Royal Society of Tasmania 122(1): 255-263.

Shaw, J.S., Hovenden, M.J. \& Bergstrom, D.M. 2005: The impact of introduced ship rats (Rattus rattus) on seedling recruitment and distribution of a subantarctic megaherb (Pleurophyllum hookeri). Austral Ecology 30: 118-125.
Schulz, M. \& Gales, R. 2004: Breeding of the Antarctic Tern (Sterna vittata bethunei) on Macquarie Island. Notornis 51: 114-116.

Schulz, M., Robinson, S. \& Gales, R. 2005: Breeding of the Grey Petrel (Procellaria cinerea) on Macquarie Island: population size and nesting habitat. Emu 105: 323-329.

Scofield, R.P. \& Wiltshire, A. 2004: Snow Petrel (Pagodroma nivea) records from Macquarie Island. Еmu 67: 1-22.

Skira, I.J. 1978: Reproduction of the rabbit, Oryctolagus cuniculus (L.), on Macquarie Island, subantarctic. Australian Wildlife Research 5: 317-326.

Skira, I.J. 1980: Some population parameters and seasonal changes in the weights of internal organs of rabbits. Oryctolagus cuniculus (L.), at Macquarie Island. Australian Wildlife Research 7: 235-245.

Skira, I.J. 1984: Breeding distribution of the Brown Skua on Macquarie Island. Emu 84(4): 248-249.

Sullivan, B.J., Reid, T.A. \& Bugoni, L. 2006: Seabird mortality on factory trawlers: the Falkland Islands experience. Biological Conservation 131: 495-504.

Taylor, B.W. 1955: The flora, vegetation and soils of Macquarie Island. ANARE Reports. B(2) No. 19, Botany: 190 pp.

Taylor, R.H. 1979: How the Macquarie Island parakeet became extinct. New Zealand Journal of Ecology 2: 42-45.

Threatened Species Section 2007: Draft Fauna Recovery Plan: Macquarie Island Burrowing Petrels 2007-2011. Department of Primary Industries and Water, Hobart: $61 \mathrm{pp}$.

Tweedie, C.E. 2000: Climate change and the autecology of six plant species along an altitudinal gradient on subantarctic Macquarie Island. Bulletin of the Ecological Society of Australia 31(4): 27-28

Tweedie, C.E. \& Bergstrom, D.M. 2000: A climate change scenario for surface air temperature at subantarctic Macquarie Island. In Davison, W. (ed.): Proceedings of the VII SCAR International Biology Symposium, Christchurch, New Zealand, 31 August -4 September. Warham, J. 1990: The Petrels: their Ecology and Breeding Systems. Academic Press, London: 440 pp.

Waugh, S.M., Cabrera, H., Wood, G.C. \& Davis, L.S. 2003: Burrow occupancy in Westland Petrels (Procellaria westlandica). Notornis 50(3): 123-127.

Weimerskirch, H., Catard, A., Prince, P.A., Cherel, Y. \& Croxall, J.P. 1999: Foraging white-chinned petrels Procellaria aequinoctialis at risk: from the tropics to Antarctica. Biological Conservation 87(2): 273-275.

Whinam, J. \& Copson, G. 2006: Sphagnum moss: an indicator of climate change in the subantarctic. Polar Record 42(220): 43-49.

(accepted 7 October 2008) 